\title{
WestVirginiaUniversity
}

THE RESEARCH REPOSITORY @ WVU

Graduate Theses, Dissertations, and Problem Reports

2009

\section{An experimental analysis of jackpotting}

Toshikazu Kuroda

West Virginia University

Follow this and additional works at: https://researchrepository.wvu.edu/etd

\section{Recommended Citation}

Kuroda, Toshikazu, "An experimental analysis of jackpotting" (2009). Graduate Theses, Dissertations, and Problem Reports. 2799.

https://researchrepository.wvu.edu/etd/2799

This Thesis is protected by copyright and/or related rights. It has been brought to you by the The Research Repository @ WVU with permission from the rights-holder(s). You are free to use this Thesis in any way that is permitted by the copyright and related rights legislation that applies to your use. For other uses you must obtain permission from the rights-holder(s) directly, unless additional rights are indicated by a Creative Commons license in the record and/ or on the work itself. This Thesis has been accepted for inclusion in WVU Graduate Theses, Dissertations, and Problem Reports collection by an authorized administrator of The Research Repository @ WVU. For more information, please contact researchrepository@mail.wvu.edu. 


\title{
An Experimental Analysis of Jackpotting
}

\author{
Toshikazu Kuroda \\ Thesis submitted to the Eberly College of Arts and Sciences at \\ West Virginia University \\ in Partial Fulfillment of the Requirements for the Degree of \\ Master of Science \\ in \\ Psychology
}

Kennon A. Lattal, Ph.D., Chair

Michael Perone, Ph.D.

Daniel E. Hursh, Ph.D.

Department of Psychology

Morgantown, West Virginia

2009

Keywords: reinforcer magnitude, fixed-interval performance, pigeons 


\section{ABSTRACT \\ An Experimental Analysis of Jackpotting \\ Toshikazu Kuroda}

This experiment assessed effects of jackpotting, defined as the delivery of a larger than usual reinforcer, on responding of pigeons maintained by fixed-interval (FI) schedules. In baseline conditions, reinforcer duration was 1-s and all such reinforcers were delivered from the hopper located on the main work panel. During jackpot conditions, a 1-s reinforcer occasionally was replaced by a 7-s reinforcer (jackpot) delivered from a second hopper located at the rear of the chamber. Sham jackpot conditions also were studied. These sham conditions were identical to the jackpot conditions with one exception: A 1-s, instead of 7-s, reinforcer was delivered from the back hopper. Jackpotting occasionally suppressed rather than enhanced FI responding, which seems to contradict descriptions of its effects in the animal-training literature. While the subjects were not key pecking, however, they were inserting their heads into the back hopper. This result suggests that jackpots reinforce the consummatory response, thereby reducing the rate of operant responding. These findings may be related to incentive contrast, reinforcement omission, the concept of "surprise" in Pavlovian conditioning, response reinstatement, and conditioned emotional responses. 


\section{Acknowledgements}

I want to begin by thanking members of my committee. First and foremost, I thank Andy for the constructive advice and insight for my experiment throughout the project and for being patient with setting up apparatus in the lab. He gave me an opportunity to learn by interacting with the subject matter. Without his help, this project would not have been successful. I thank Mike for sharing his constructive critiques on the experimental procedure and for teaching me the Visual Basic programming language for data analyses. I thank Dr. Hursh for his genuine willingness to serve a committee member and for asking insightful questions about applications of the experiment.

I thank Yusuke Hayashi for having discussed conceptual issues in behavior analysis, which significantly helped me think of the present research topic in relations with other research topics. I thank Ezra Hall, my undergraduate research assistant, for running sessions in the second half of the experiment. Lastly, I want to thank my parents for teaching me the determination and perseverance in me to achieve this goal. 
Table of Contents

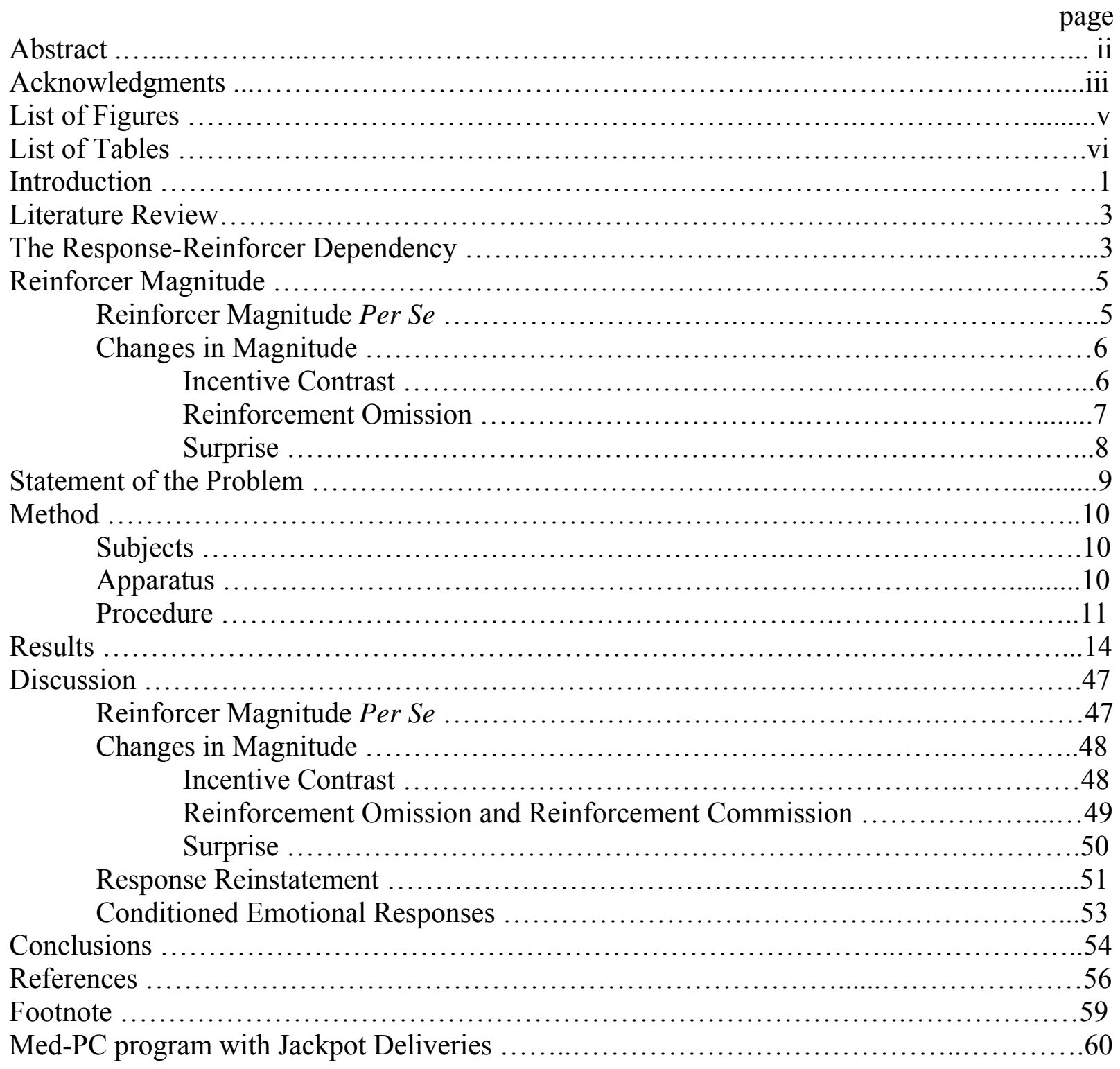




\section{List of Figures}

page

Figure 1. Response rate as a function of successive sessions

Figure 2. Running rate as a function of successive sessions

Figure 3. Post-reinforcement pause as a function of successive sessions

Figures 4a-c. Mean local response rate during the first, fifth, tenth, and last sessions of each experimental condition 20

Figures $5 a-c$. Mean local running rate during the first, fifth, tenth, and last sessions of each experimental condition

Figures 6a-c. Mean local post-reinforcement pause during the first, fifth, tenth, and last sessions of each experimental condition

Figure 7. Cumulative responses in successive 5-s bins for randomly selected 10 consecutive FIs during the last session of the first baseline 32

Figures 8a-c. Cumulative responses in successive 5-s bins across successive jackpot deliveries during the first session of each experimental condition

Figures 9a-c. Cumulative responses in successive 5-s bins across the FI terminating with the first jackpot that occurred during each of these sessions and the two successive FIs following that jackpot delivery during the first, fifth, tenth, and last sessions of each experimental condition

Figures 10a-c. The number of intervals in which hopper-checking occurred at least once as a function of successive sessions

Figures 11a-c. The number of back hopper-checking that occurred within an interval as a function of successive sessions 
List of Tables

page

Table 1: A Summary of a Sequence of Conditions and the Number of Sessions..................13 
The concept of jackpotting developed in the animal training literature, where it has been defined as the delivery of a larger than usual reinforcer, either dependent on a response (Burch \& Bailey, 1999) or independently of responding (Pryor, 1984). Pryor, for example, suggested that a jackpot is "a reward that is much bigger, maybe ten times bigger, than normal reinforcement, and one that comes as a surprise to the subject" (p. 31). In contrast to the small pieces of food that animal trainers typically encourage owners to use in training the behavior of their pets, it has been suggested that a jackpot has a disproportionally strong effect on behavior. For example, describing the delivery of a response-dependent jackpot as "giving the [animal] a large, unexpected reinforcer" (p. 44, italics added), Burch and Bailey noted that "jackpotting results in an animal that is excited and curious about what might be coming next" (p. 44). Pryor described a similar outcome of jackpotting in the following anecdote about one of the dolphins she was training:

Our subject was a docile animal named Hou that rarely offered new responses. When she failed to get reinforced for what she did offer, she became inactive, and finally in one session she went twenty minutes offering no responses at all. The trainer finally tossed her two fish "for nothing." Visibly startled by this largesse, Hou became active again and soon made a movement that could be reinforced, leading to real progress in the next few sessions (Pryor, 1984, p. 32)

Pryor also described an experience in her adolescence in which a free riding ticket (which she described as a response-independent jackpot) relieved her "truculent and disagreeable" (p. 32) feelings.

Furthermore, the inverse of jackpotting also has been described anecdotally in the psychological literature. Tinklepaugh (1928) replaced a banana with a piece of lettuce in an 
experiment in which he was attempting to test a monkey's reaction to the qualitative change in rewards, he observed the following:

She extends her hand to seize the food. But her hand drops to the floor without touching it. She looks at the lettuce, but (unless very hungry) does not touch it. She looks around the cup and behind the board. She stands up and looks under and around her. She picks the cup up and examines it thoroughly inside and out. She has on occasions turned toward observers present in the room and shrieked at them in apparent anger. After several seconds spent searching, she gives a glance toward the other cup, which she has been taught not to look into, and then walks off to a nearby window. The lettuce is left untouched on the floor. (pp. 224-225).

Each of these anecdotes suggests that an abrupt change in some aspects of reinforcement may have a strong effect on ongoing behavior. All of these anecdotes are rather general, imprecise, and not necessarily objective. In the case of jackpotting they also are mentalistic. Despite the fact that jackpotting was first described more than two decades ago, empirical studies of its effects have not been forthcoming. Thus, the effects of jackpots are limited to anecdotes like those reported above. Given the paucity of data, empirical investigation is invited.

In the section that follows, several areas of research that seem to be related to different variables that might contribute to the jackpotting effect are reviewed. One variable is the response-food delivery relation. Responding maintained by response-dependent food delivery is altered by response-independent food delivery. Pryor (1984), however, claimed that the food need not be response-dependent to have its facilitative effect on behavior. Research on the response-reinforcer dependency contradicts Pryor's assertions. Research related to the effects of reinforcer magnitude bears on jackpotting in two ways: the size of reinforcer per se and the 
change in magnitude. At least in some conditions, larger reinforcers have stronger effects on responding than do smaller reinforcers. With regard to the change in magnitude, three other areas of research seem relevant to the effects of jackpotting: incentive contrast, reinforcement omission, and so-called "surprise." The description of incentive contrast bears some similarity to the increase in responding described in the anecdotes about jackpotting. Reinforcement omission, on the other hand, shares a common feature with jackpotting in the sense of the momentary change in reinforcer magnitude. Lastly, in jackpotting the abrupt increase in reinforcer magnitude may be related to "surprise," which has been suggested to strengthen a conditional stimulus-unconditional stimulus (CS-US) association in Pavlovian conditioning. Each of these areas is discussed in turn in literature review. Then the review is followed by an experimental analysis of several variables that may shed light on the phenomenon labeled jackpotting.

\section{Literature Review}

\section{The Response-Reinforcer Dependency}

One variable that has been suggested to operate in conjunction with jackpotting is the response-reinforcer dependency. As noted, jackpotting has been defined either responsedependent or response-independent. Unlike the suggestions of some of the anecdotes about jackpotting, response-independent food delivery has been shown to have different behavioral effects from response-dependent food delivery. After establishing responding with a fixedinterval (FI) or a variable-interval (VI) schedule, for example, Zeiler (1968) switched these schedules to either a fixed-time (FT) or a variable-time (VT) schedule in which the reinforcers were delivered independently of responding. This change in the dependency decreased response rates. 
It should be noted that in Pryor's anecdotes a response-independent jackpot was delivered while response-dependent reinforcers also were available. In Burch and Bailey's anecdote, on the other hand, both the jackpot and the standard food presentation were response-dependent. In this respect, the former is similar to schedules of reinforcement combining response-dependent and response-independent food deliveries, whereas the latter is similar to schedules of reinforcement consisting of two separate schedules of responsedependent reinforcement. Using concomitant VI VT schedules, Lattal (1974) varied the percentage of food deliveries that were response-independent. Higher percentages of responseindependent reinforcers resulted in lower response rates. Similarly, Lattal and AbreuRodrigues (1997) compared response rates in VI schedules with that in concomitant VI FT schedules by varying the ratios of response-independent to response-dependent reinforcers while holding either FT values (Experiment 1) or VI values (Experiment 2) constant. In both experiments, the rates in the presence of response-independent reinforcement were generally lower than in the absence. The procedure that Lattal and Bryan (1976, Experiment 2) used is more directly relevant to the comparison between Pryor's and Burch and Bailey's anecdotes. These researchers used a multiple (concomitant ${ }^{1}$ FI VT) (conjoint FI VI) schedule: Each component is related to response-independent and response-dependent jackpotting procedures, respectively. The former component generally maintained lower rates than the latter.

In short, the results of these studies suggest that response-independent jackpotting would likely decrease, rather than increase, response rate. Because of the response-decelerating effects almost always found when reinforcers are delivered independently of responding, the present study investigated response-dependent jackpotting. 


\section{Reinforcer Magnitude}

A second major feature of jackpotting is that it involves a change in reinforcer magnitude. There are two aspects of magnitude that bear on jackpotting: the size of reinforcer per se and the change from one magnitude to another. Each is discussed below.

\section{Reinforcer Magnitude Per Se}

Greater reinforcer magnitudes, intuitively, should have stronger effects on responding. But this is not always the case. In their review of reinforcement magnitude effects, Bonem and Crossman (1988) pointed out that "changes in the magnitude of reinforcement do not always produce changes in response, particularly on simple schedules of reinforcement" (p. 348). For example, using a concurrent VI VI schedule and a simple VI schedule, Catania (1963) showed that response rates were sensitive to changes in reinforcement duration in the former schedule (i.e., there was a positive correlation between the rates and the durations) but not in the latter.

The effects of reinforcer magnitude are less clear in experiments using a multiple schedule. Keesey and Kling (1961) varied the size of reinforcer daily in a three-component multiple schedule. They failed to find a systematic relation between reinforcer size and response rate. Using a multiple VI 2-min VI 2-min schedule, Shettleworth and Nevin (1965) varied reinforcer durations in each component, revealing consistently higher response rates in the richer components than in the leaner components.

Furthermore, contrary to the intuition, longer reinforcer durations actually decrease response rates under some circumstances. For example, varying reinforcer durations in an FI schedule, Staddon (1970) showed that longer reinforcer durations led to longer postreinforcement pauses (PRPs), lowering overall response rates. Lowe, Davey, and Harzem (1974) replicated this result. 
In short, the effects of the size of reinforcer per se are inconsistent across experiments. Thus, it is difficult to interpret the effects of jackpotting described in the anecdotes merely in terms of its reinforcer magnitude.

\section{Changes in Magnitude}

Another effect of reinforcer magnitude is observed when it is changed from one circumstance to another. This has been discussed in two areas of research: incentive contrast and reinforcement omission. In addition, these two areas share a common element, so-called "surprise," that has been discussed in the literature of Pavlovian conditioning. Each of these areas is discussed in turn.

Incentive contrast. The description of incentive contrast is similar to the increase in responding described in the anecdotes about jackpotting. Incentive contrast was first described by Crespi (1942). There were two groups of rats in his experiment with a runway. In one of the groups, there was a transition from a smaller reinforcer to a larger reinforcer. The other group continued receiving a larger reinforcer from the beginning. The running speed of the former group increased after the transition in reinforcer magnitude and, more importantly, the speed was faster than that of the latter group. This is called overshooting or positive incentive contrast. The disproportionally strong effects of jackpotting appear similar to overshooting. (Crespi also described undershooting, or negative incentive contrast, whereby the speed was slower for a group of rats which experienced a transition from a larger to a smaller reinforcer than the other group which continued receiving a smaller reinforcer from the beginning.)

Flaherty (1982) pointed out that one factor that may influence the degree of incentive contrasts is reward disparity. In general, "[t]he greater the difference between large and small reward, the greater is the contrast" (p. 414). The major difference between incentive contrast and jackpotting, however, is that the change in an amount of reinforcer is chronic in the former 
whereas the change is acute in the latter. Thus, the findings from studies of incentive contrast apply to jackpotting to the extent that momentary rather than chronic delivery of large reinforcers may affect subsequent responding.

Reinforcement omission. Jackpotting can be viewed as the inverse of reinforcement omission. Reinforcement omission refers to the temporary removal or substitution of a reinforcer without a change in the basic schedule of reinforcement. The omission generally results in changes in responding maintained by the basic schedule. For example, using pigeons and rats, Staddon and Innis (1969, Experiment 1) employed a procedure in which odd numbered intervals (first, third, and so on) of an FI 2-min schedule had a $50 \%$ probability of replacement of reinforcement with a timeout of the same duration as the reinforcer. Response rates of each subject were higher after the reinforcement omission than after reinforcement. They suggested that the increased rate was due to the shorter PRPs that were obtained after the omission than after reinforcement. Indeed, reinforcement omission did not affect running rates. Reinforcement omission does not necessarily result in higher response rates. Staddon (1972) used the Staddon and Innis (1969, Experiment 1) procedure with one modification: In odd numbered intervals, they used a tandem differential-reinforcement-of-other-behavior (DRO) variable-interval (VI) schedule, which produced positively accelerated key peck responding (so-called "No-Go-Go"), and tandem VI DRO schedule, which produced negatively accelerated responding (so-called "Go-No-Go"). Reinforcement omission increased responding in the No-Go-Go procedure whereas it decreased responding in the Go-No-Go procedure.

The degree of dissimilarity between the conditions of reinforcement and the nature of the omission affects the omission effect. Kello (1972) compared the effects of reinforcement (R) with blackout alone (B), blackout plus magazine light (ML), and complete reinforcement 
omission without any stimulus change (0). The magnitude of response rates was $\mathrm{R}<\mathrm{B}+\mathrm{ML}<$ $\mathrm{B} \leq 0$. That is, response rate was higher in the more dissimilar condition to the condition of reinforcement (B) than in the less dissimilar condition (B+ML).

Studies of reinforcement omission suggest that an acute change in reinforcer magnitude results in changes in regular responding. Perhaps, jackpotting shares the same element but with the opposite direction of change in reinforcer magnitude. Moreover, Kello's (1972) results suggest that the dissimilarity between a jackpot and a normal reinforcer may be an important factor in determining the effects of a jackpot reinforcer.

Surprise. In jackpotting, the abrupt increase in reinforcer magnitude may be "surprising." Incentive contrast and reinforcement omission each, indeed, share this as a common element in the sense that changes in reinforcer magnitude in these cases may be surprising. Supporting this view, Flaherty (1982) suggested that varied or gradual shifted reinforcer magnitude (thereby attenuating unpredictability) is unlikely to produce incentive contrasts. Surprise has been discussed mainly in the literature of Pavlovian conditioning. According to Kamin (1969), Pavlovian conditioning is a result of surprising or unpredicted occurrence of US event in the presence of CS. Similarly, Rescorla and Wagner (1972) made the following statement:

[O]rganism only learn when events violate their expectations. Certain expectations are built up about the events following a stimulus complex; expectations initiated by that complex and its component stimuli are then only modified when consequent events disagree with the composite expectation (p. 75).

Their statement also suggests that the frequent presentations of US in the presence of CS gradually attenuate the change in their associative strength. Similarly, Burch and Bailey pointed out that the overuse of jackpotting is "likely [to diminish] the value of the jackpot" (p. 
45). In short, the function of surprise in Pavlovian conditioning is similar to that of jackpotting. The effects of jackpotting described in the animal training literature may be attributed to the stochastic occurrence of a large increase in reinforcer magnitude.

\section{Statement of the Problem}

Jackpotting has been defined as the delivery of a larger than normal reinforcer either dependent on a response or independently of responding. Despite the fact that jackpotting was first described more than two decades ago, empirical studies of jackpotting have not been forthcoming. There are, however, several research areas that relate to jackpotting. One relevant area is that related to the effects of the response-reinforcer dependency. A responseindependent food delivery generally reduces rather than facilitates responding (Lattal, 1974; Lattal \& Abreu-Rodrigues, 1997; Lattal \& Bryan, 1976; Zeiler, 1968). Because the results of these studies suggest that response-independent jackpotting decrease rather than increase a response rate, the present study employed only response-dependent jackpotting.

A second related area is reinforcer magnitude. The effects of the size of reinforcer on responding per se are mixed. The literature about the changes in magnitude, on the other hand, provides more relevant findings to jackpotting. For example, a transition from a smaller to a larger reinforcer magnitude results in higher responding, and it sometimes leads to overshooting or positive incentive contrast (Crespi, 1942). Because the changes in reinforcer magnitude typically are chronic, however, they differ from the momentary change that defines jackpotting. This momentary change may be regarded as similar to both reinforcement omission and surprise in Pavlovian conditioning. A large, randomly presented reinforcer may be "surprising" in the same way that an associative strength of CS-US increases in Pavlovian conditioning (Kamin, 1969; Rescorla \& Wagner, 1972). Procedurally, a large, randomly 
presented reinforcer shares this element of surprise with reinforcement omission, perhaps, with an opposite effect on behavior.

Each of the behavioral procedures reviewed above is similar to jackpotting, but the descriptions of the behavioral effects of jackpotting are limited to its anecdotes. Specifically, it is little known about the effects of the momentary increases in reinforcer magnitude. The purpose of this study, then, was to empirically examine some of the effects of delivering "jackpot" reinforcers on responding maintained by interval schedules of reinforcement.

Method

\section{Subjects}

Three experimentally naïve White Carneau pigeons served (Pigeons 967, 4140, and 4141). Each was housed individually in a home cage with continuous access to water and health grit. Each pigeon was maintained at 80 percent of its ad libitum body weight by feedings provided at least 30 min after a session when necessary.

Apparatus

Two almost-identical operant conditioning chambers, located in a sound-attenuating experimental room, were used. The work area of each chamber was $32 \mathrm{~cm}$ long by $30 \mathrm{~cm}$ high by $30 \mathrm{~cm}$ wide. A front aluminum work panel, comprising one wall of the chamber, displayed 1.90-cm diameter response keys. Only the center key (for P967 and P4141) or the left key (for P4140) was operative. The operative key was transilluminated by a red 28 -vdc bulb was operated by a force of approximately $0.15 \mathrm{~N}$. A hopper was located behind a $4.5 \mathrm{~cm}$ square feeder aperture located on the midline of the work panel $9 \mathrm{~cm}$ from the floor. A back work panel, comprising the opposite side of the chamber, had another hopper in a corresponding location. Reinforcement was access to mixed grain from either hopper. During reinforcement, the keylight was turned off, and the hopper was raised into the aperture, which was illuminated 
by a white or green feeder light on the front or back panel, respectively. Each aperture housed a photocell. A camera $(3 \mathrm{~cm} \times 3 \mathrm{~cm} \times 2 \mathrm{~cm})$ was set on the ceiling of the operant chamber to monitor a pigeon's behavior on a screen in an adjacent room. White noise masked extraneous noise. An IBM-compatible personal computer, located in the adjacent room, operated medpc7 software which in turn controlled the experiment and recorded the data. SoftCR software produced a cumulative record of responding during each session.

Procedure

Preliminary training. The pigeons first were magazine trained with the front hopper and then the key peck response was shaped by differential reinforcement of successive approximations during the first sessions of the experiment. After the development of key pecking, an FR 1 schedule was in effect whereby each reinforcer was 1-s, which began when the pigeon inserted its head in the aperture and broke the photocell, thereby activating a 1-s timer. The ratio was increased gradually up to 30 . Then, an FI 15-s schedule was in effect. The interval was increased daily in increments of 15 -s up to 45 -s.

Table 1 summarizes the sequence of conditions and the number of sessions at each for each pigeon. Each condition remained in effect for at least 20 sessions, and until the stability criteria described below were met. Initially, sessions began with a 180-s blackout and ended after 60 reinforcers have been presented (approximately $65 \mathrm{~min}$ ). The duration of the blackout was increased to 300-s during the first baseline for all pigeons because P4141 sometimes did not start pecking after $180 \mathrm{~s}$. In the front hopper, the duration of all reinforcers was 1 -s. In the back hopper, jackpot reinforcers were 7-s in duration in what are described as Rich and Lean conditions. In the Sham Rich and Sham Lean conditions, which also are described below, the duration of food delivery from the back hopper was 1-s. As in the training condition, the reinforcement cycle commenced when, upon activation of the food hopper, the pigeon broke 
the photocell beam across the aperture with its head. It was found, however, during the first baseline, the photocell beam was not working reliably in the front hopper of the chamber for P4140. Thus, the requirement to break the front photocell beam was removed for that pigeon and, instead, the reinforcer duration from the front hopper was increased to 1.5 -s in an attempt to equate the actual duration of access to the mixed grain to other two pigeons. The conditions were as follows.

Baseline. An FI 60-s schedule was in effect before and after each of the experimental conditions described below. All reinforcers were delivered from the front hopper.

Experimental conditions. Experimental conditions were identical to the baseline condition except that in all but the first two and last two intervals in each session, the 1-s reinforcer sometimes was replaced by a 7-s reinforcer (jackpot) or a 1-s reinforcer (sham jackpot) from the back hopper. In the Lean conditions, one jackpot was substituted randomly for one of the 1-s reinforcers between the 3rd and 30th interval and another between the 31 st and 58th interval. Thus, there were two jackpots per session. In the Rich conditions, two jackpots were substituted randomly for1-sreinforcers between the 3rd and 30th interval and another two between the 31 st and 58th interval, resulting in four jackpots per session. The Sham Lean and the Sham Rich conditions were identical to the Lean and the Rich conditions, respectively, except that jackpots were replaced by sham jackpots (see above). In all the experimental conditions, there was a restriction on the food delivery from the back hopper: No more than two deliveries of jackpot could occur consecutively. The restriction was to be accomplished by forcing the third food delivery to be a 1-s reinforcer from the front hopper. The restriction potentially could reduce the total number of jackpots (or sham jackpots) within a session; however, this did not happen over the entire course of the experiment. 
Table 1

A Summary of a Sequence of Conditions and the Number of Sessions.

Seq. Pigeon $967 \quad$ Pigeon $4140 \quad$ Pigeon 4141

\begin{tabular}{llll}
\hline 1. & Baseline (18) & Baseline (25) & Baseline (25) \\
2. & Rich (41) & Rich (32) & Lean (23) \\
3. & Baseline (28) & Baseline (25) & Baseline (57) \\
4. & Lean (26) & Lean (26) & Rich (20) \\
5. & Baseline (64) & Baseline (36) & Baseline (25) \\
6. & Sham Rich (22) & Sham Rich (50) & Sham Lean (24) \\
7. & Baseline (25) & Rich (35) & Baseline (46) \\
8. & Rich (30) & Sham Rich (-) & Lean (25) \\
9. & Sham Rich (25) & & \\
10. & Rich (-) & & \\
\hline
\end{tabular}

Note. The total number of jackpots per session was two and four in the Lean and Rich conditions, respectively. The Sham Lean and Sham Rich conditions were identical to the Lean and Rich conditions except that a jackpot was replaced by a sham jackpot.

a. An actual number of sessions spent during the first baseline was greater than the value shown on this table for each pigeons. For P967 and P4141, the table shows the number of sessions after being moved to a different operant chamber. For P4140, the table shows the number after the requirement of breaking photocell in the front hopper was removed (read texts for details). b. The condition has not completed yet. 
Stability criteria. Stability was assessed with the following measures differing by no more than \pm 0.05 of the mean of last six consecutive sessions, without any trends: mean PRPs and running rates. In addition, cumulative records were inspected to assess the patterns of responding in FI intervals of all conditions. Sessions generally occurred at about the same time 7 days a week, with few exceptions (e.g., apparatus failure, injury of subjects, or the experimenter's absence to attend a conference).

Results

Results are described in the order of P967, P4140, and P4141 unless specified otherwise; letters $(\mathrm{a}, \mathrm{b}$, and $\mathrm{c})$ in the figures correspond to these pigeons in the same order.

\section{Global Measures}

Global measures included response rate [(a total number of responses) / (session time)], running rate [(a total number of responses) / (session time - a total duration of pause time)], and mean PRP [(a total duration of pause time) / 60]. Time spent in reinforcement was excluded from all calculations.

It would have been ideal to exclude the first interval from the calculation of response rate and running rate; however, this was not done early in the experiment. Therefore, because running rate was used for a stability criterion, no change was made in the way of calculation thereafter (Note: The same issue was raised for response rate and no change was made as well). On the other hand, the interval between the initiation of session and the first response was excluded from the calculation of mean PRP throughout the experiment. If a PRP was longer than 60-s in an FI interval (which seldom happened), the response was counted as an increment in numerator but there was no change in numerator; overall effect was negligible. 


\section{Response Rates}

Figure 1 shows response rates during all sessions of the experiment. There was a shortterm increase in the rate in the first and second Rich condition, but not in the Lean condition with P4140. There were no systematic changes in response rates for P967 and P4141.

\section{Running Rates}

Figure 2 shows running rates during all sessions of the experiment. The rates decreased in some of the jackpot conditions, specifically, in the Lean and second Rich conditions in both P967 and P4140 and the first Lean condition for P4141. These results, however, should be considered with caution. With each pigeon, the decrease in rates observed in the first Lean condition did not reverse when a baseline was reinstated following the jackpot condition. Thus, the decreases may not be attributed to jackpotting.

\section{Mean PRPs}

Figure 3 shows the mean PRP during all sessions of the experiment. No systematic effect of jackpotting on mean PRP was observed within or between conditions for each pigeon, with one exception: For P967 and P4140, the shortest mean PRP during the experiment was observed during the first session of the first Rich condition.

\section{Summary of Global Measures}

Considering all three of the above summary measures, jackpotting did not seem to have a large or consistent effect on behavior. When there was an effect (e.g., the shortest mean of PRPs observed in the first session of the first jackpot condition in two of three pigeons), the effect either did not last long within a jackpot condition or was not replicated in subsequent conditions with jackpot delivery. Moreover, the number of jackpot deliveries (i.e., the Rich vs. Lean conditions) did not have a systematic effect. 


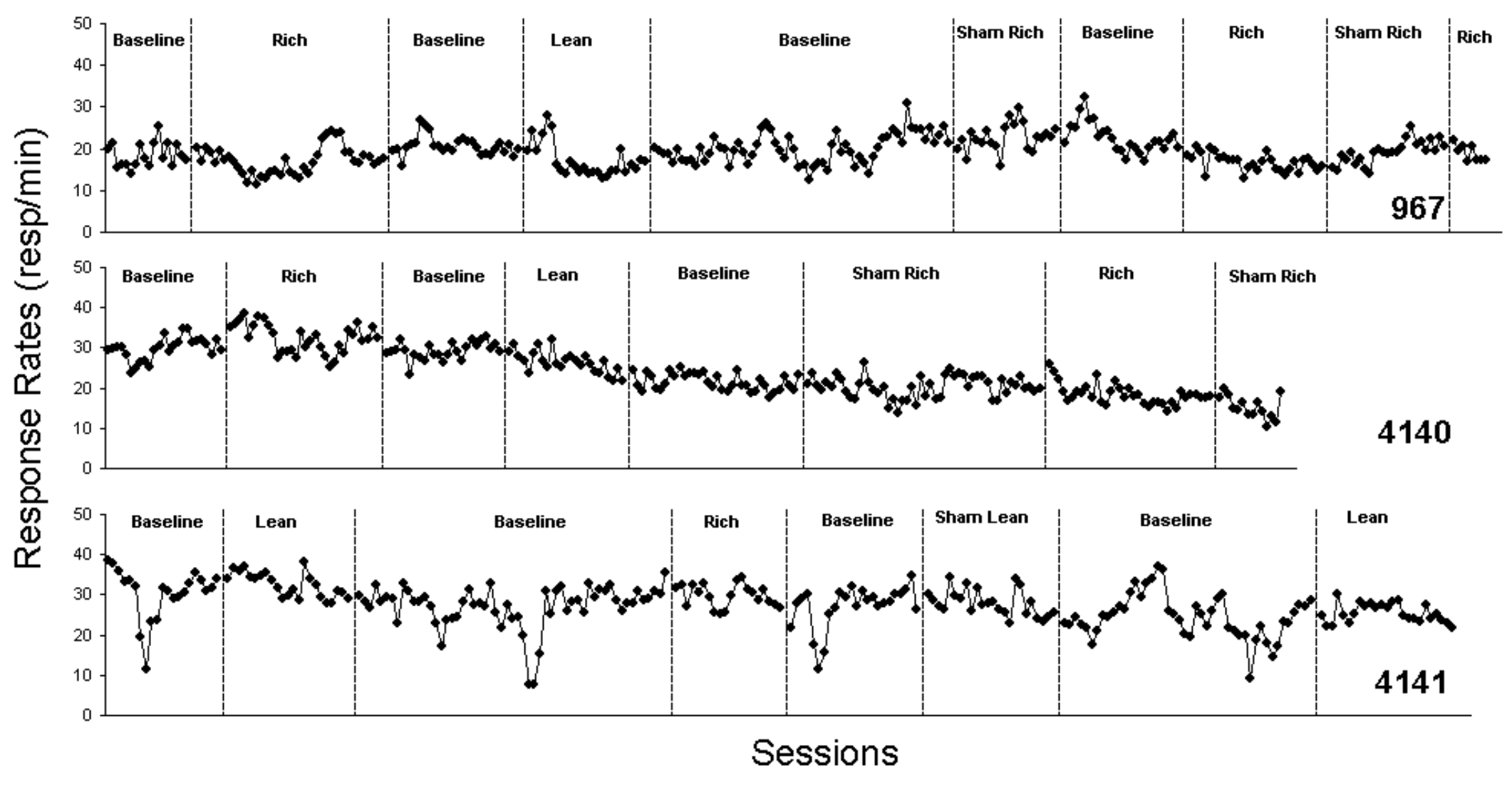

Figure 1. Response rate as a function of successive sessions 


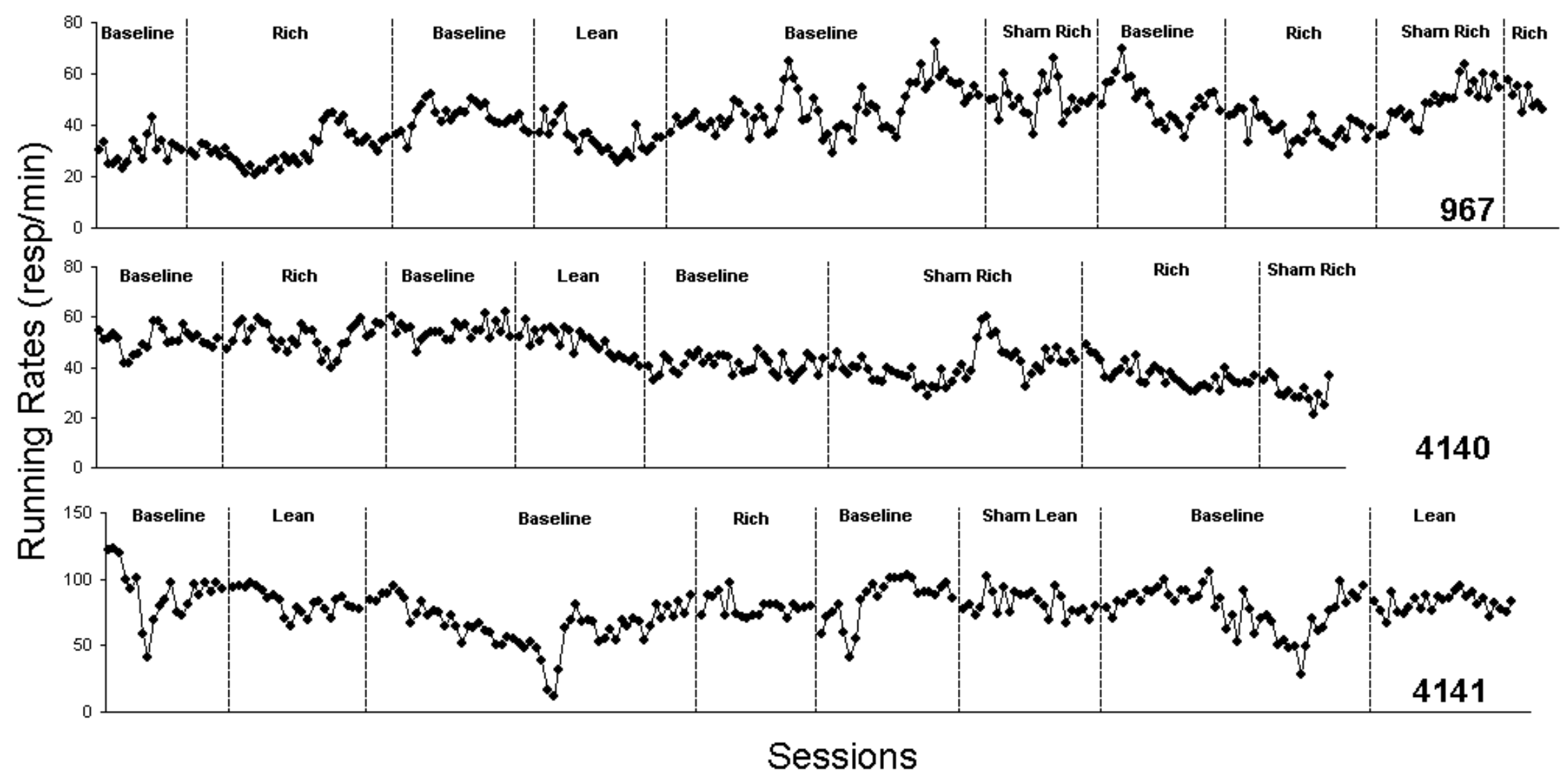

Figure 2. Running rate as a function of successive sessions 
18
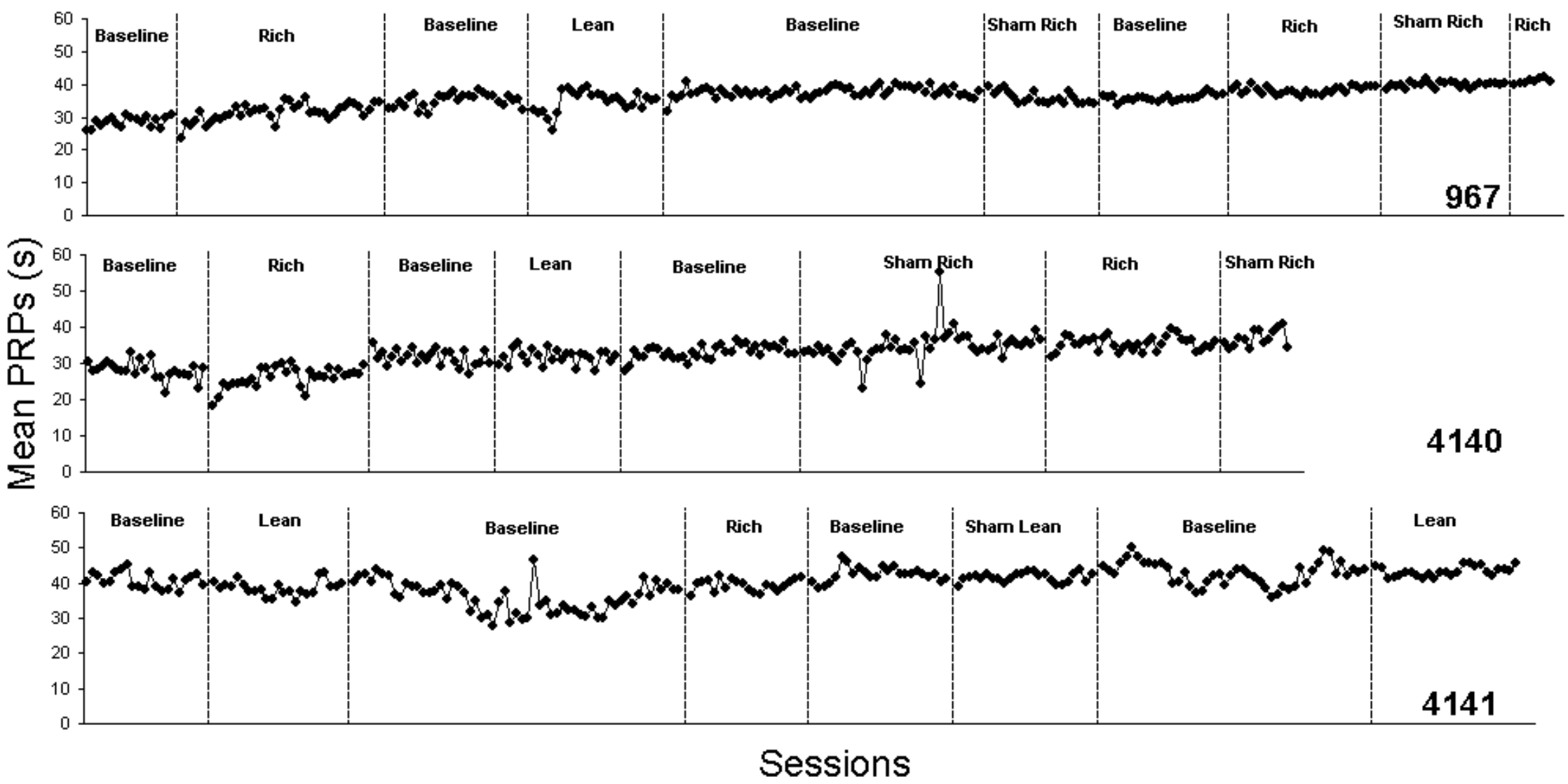

Figure 3. Post-reinforcement pause as a function of successive session 


\section{Local Measures}

Because jackpotting has been defined as a momentary increase in the magnitude of reinforcer, it was possible that its effects might have emerged more locally, that is, immediately after jackpot delivery. Accordingly, local response rates [(a total number of responses within an FI) / (a duration of the FI)], local running rates [(a total number of response within an FI) / (a duration of the FI - pause time within the FI)], and local PRPs (pause time within an FI) were measured for every FI interval. Then, the intervals that ended with a jackpot delivery (or sham jackpot delivery in the sham jackpot conditions) were analyzed, along with the two FIs that followed the jackpot. Figures 4, 5, and 6 show mean local response rates, mean local running rates, and mean local PRPs, respectively, during the three FIs just described in the first, fifth, tenth, and last sessions in each experimental condition.

Two points should be noted about the figures: First, whenever there were no responses in an interval, that interval was excluded from the analysis and a bar that would have included the interval has a thick boundary in Figures 4 and 5. Second, in case another jackpot was delivered in the first or second subsequent interval (which rarely occurred), there was no attempt to analyze data differently.

\section{Local Response Rates}

Figures 4a-c show mean local response rates. There were no systematic effects of the addition of jackpots for either P967 or P4141. For P4140, however, the mean response rates were consistently higher in the first subsequent intervals after the jackpot and sham jackpot intervals. 


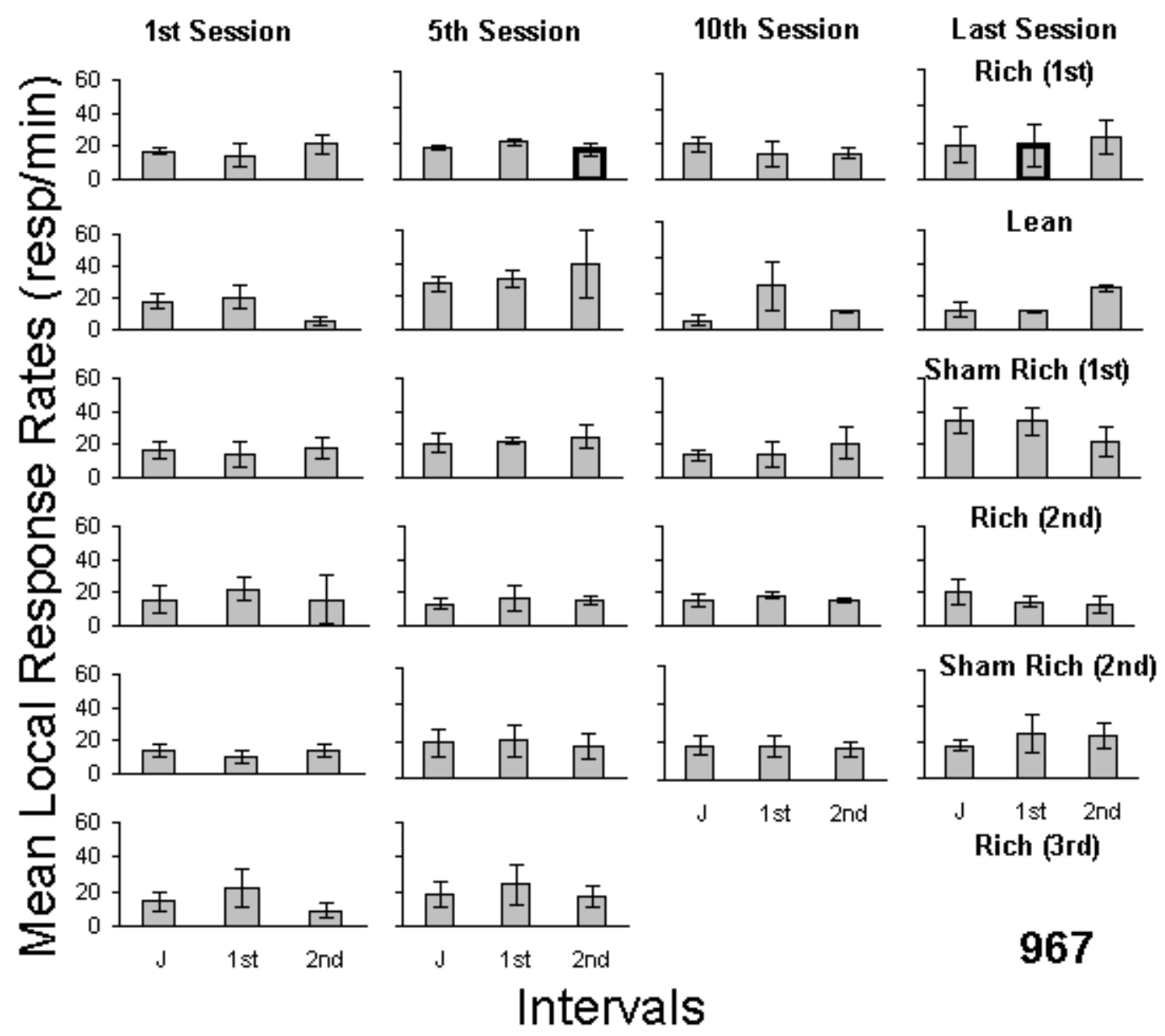

Figure 4a. Mean local response rate during the first, fifth, tenth, and last sessions of each experimental condition for P967. "J," "1st," and " 2 nd" stand for the intervals terminating with jackpot delivery and the first and second subsequent intervals after the delivery, respectively. A bolded border around the bar indicates that the value from at least one interval was excluded from the calculation for having a post-reinforcement pause of greater than $60 \mathrm{~s}$. Error bars show a range of \pm 1 standard deviation 


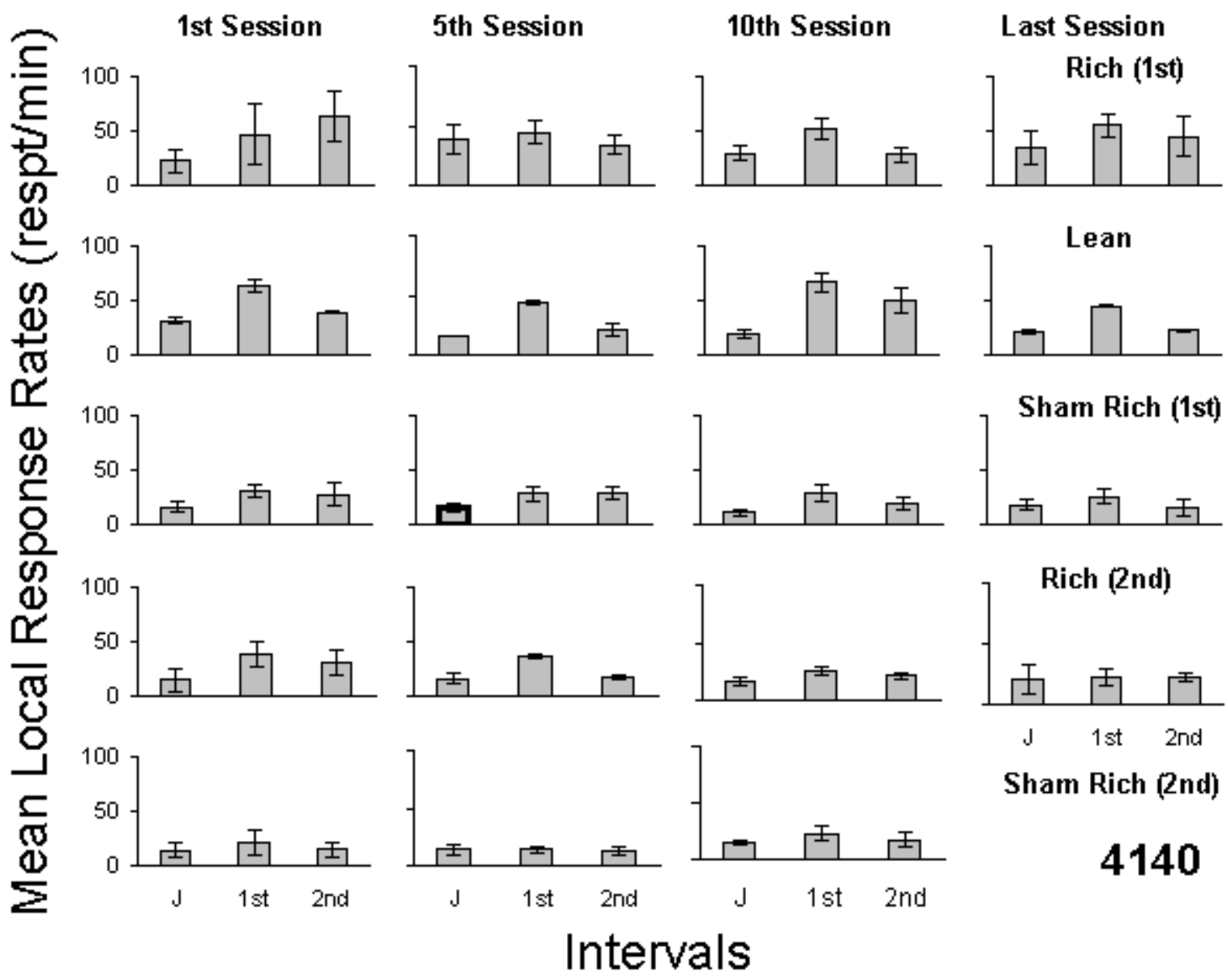

Figure $4 b$. Mean local response rate during the first, fifth, tenth, and last sessions of each experimental condition for P4140. "J," "1st," and "2nd" stand for the intervals terminating with jackpot delivery and the first and second subsequent intervals after the delivery, respectively. A bolded border around the bar indicates that the value from at least one interval was excluded from the calculation for having a post-reinforcement pause of greater than $60 \mathrm{~s}$. Error bars show a range of \pm 1 standard deviation 


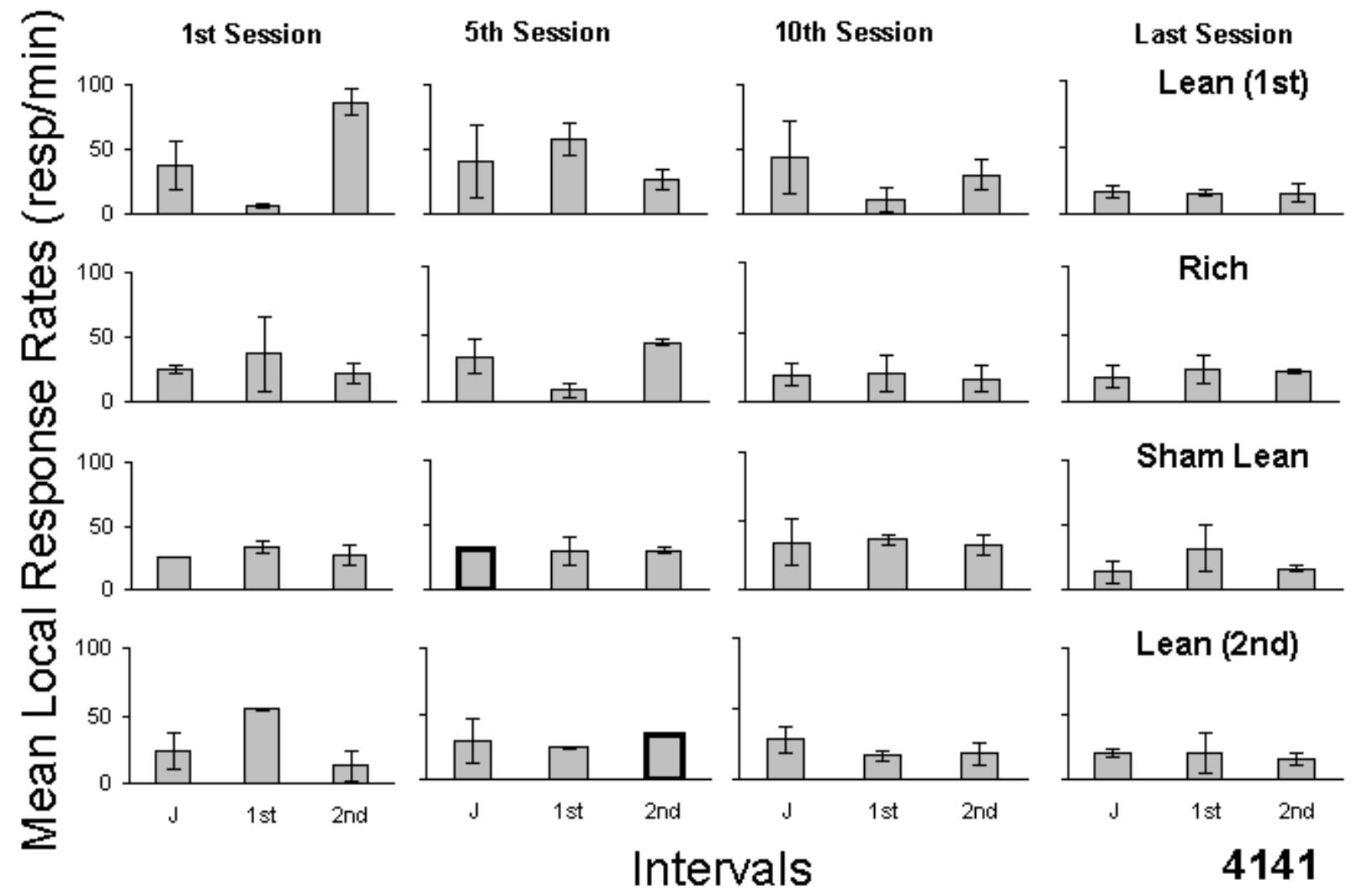

Figure 4c. Mean local response rate during the first, fifth, tenth, and last sessions of each experimental condition for P4141. "J," "1st," and "2nd" stand for the intervals terminating with jackpot delivery and the first and second subsequent intervals after the delivery, respectively. A bolded border around the bar indicates that the value from at least one interval was excluded from the calculation for having a post-reinforcement pause of greater than $60 \mathrm{~s}$. Error bars show a range of \pm 1 standard deviation 


\section{Local Running Rates}

Figures 5a-c show mean local running rates. It appears that there was not any noteworthy effect on the means of running rates in P967 and P4140. In Pigeon 4141, however, the mean in the first session of the first Lean condition was lower during the first subsequent interval than during the intervals ending with the jackpot delivery as well as during the second subsequent interval.

Mean Local PRPs

Figures 6a-c show mean PRPs. The top left graph for each pigeon shows that the PRP was shorter during the first subsequent interval than during the interval ending with the jackpot delivery. This effect did not occur in subsequent sessions of the fist Rich condition for P967. A similar effect was observed even in the sham jackpot conditions consistently for P4140. The reader's attention is directed to the last session of the second Sham Rich condition and the first session of the third Rich condition for P967 as well as to the last session of the first Sham Rich condition and the first session of the second Rich condition for P4140. These last sessions of the Sham Rich conditions were directly followed by the first sessions of the Rich conditions (see Table 1) with the only difference between them being an increase in the magnitude of reinforcer delivered from the back hopper. That is, the location of hopper and the magazine light were held constant. The fact that there was little difference in the mean in the direct transitions from the Sham Rich to the Rich conditions for the two pigeons suggests that the decrease in PRPs is likely to be attributed to the use of back hopper and/or the use of different color in magazine light but not to jackpotting per se. 


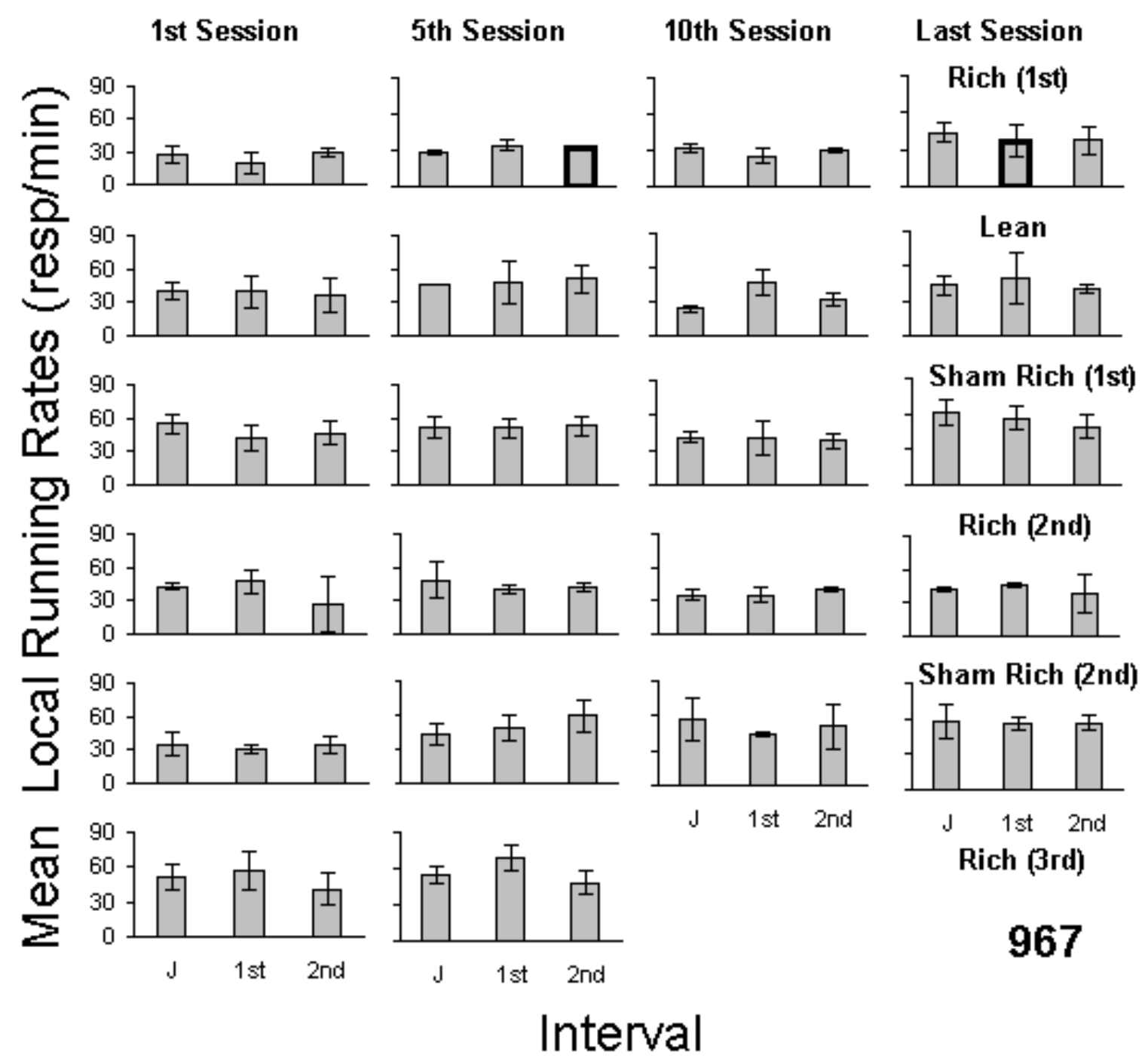

Figure 5a. Mean local running rate during the first, fifth, tenth, and last sessions of each experimental condition for P967. "J," "1st," and "2nd" indicate intervals terminating with jackpot delivery and the first and second subsequent intervals after the delivery, respectively. A bolded border around the bar indicates that the value from at least one interval was excluded from calculation for having a post-reinforcement pause of greater than 60-s. Error bars show a range of \pm 1 standard deviation 


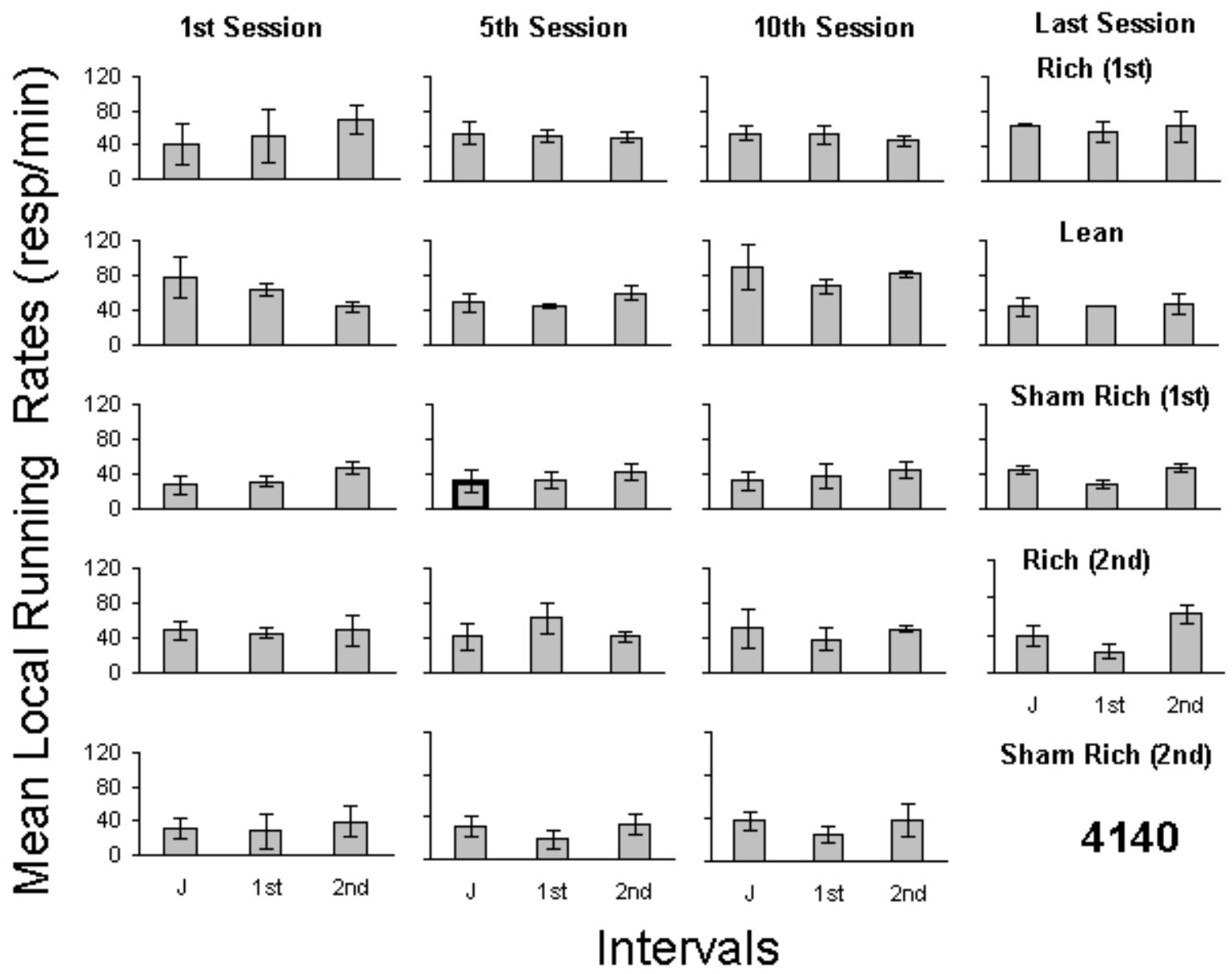

Figure 5b. Mean local running rate during the first, fifth, tenth, and last sessions of each experimental condition for P4140. "J," "1st," and " 2 nd" indicate intervals terminating with jackpot delivery and the first and second subsequent intervals after the delivery, respectively. A bolded border around the bar indicates that the value from at least one interval was excluded from calculation for having a post-reinforcement pause of greater than 60 -s. Error bars show a range of \pm 1 standard deviation 


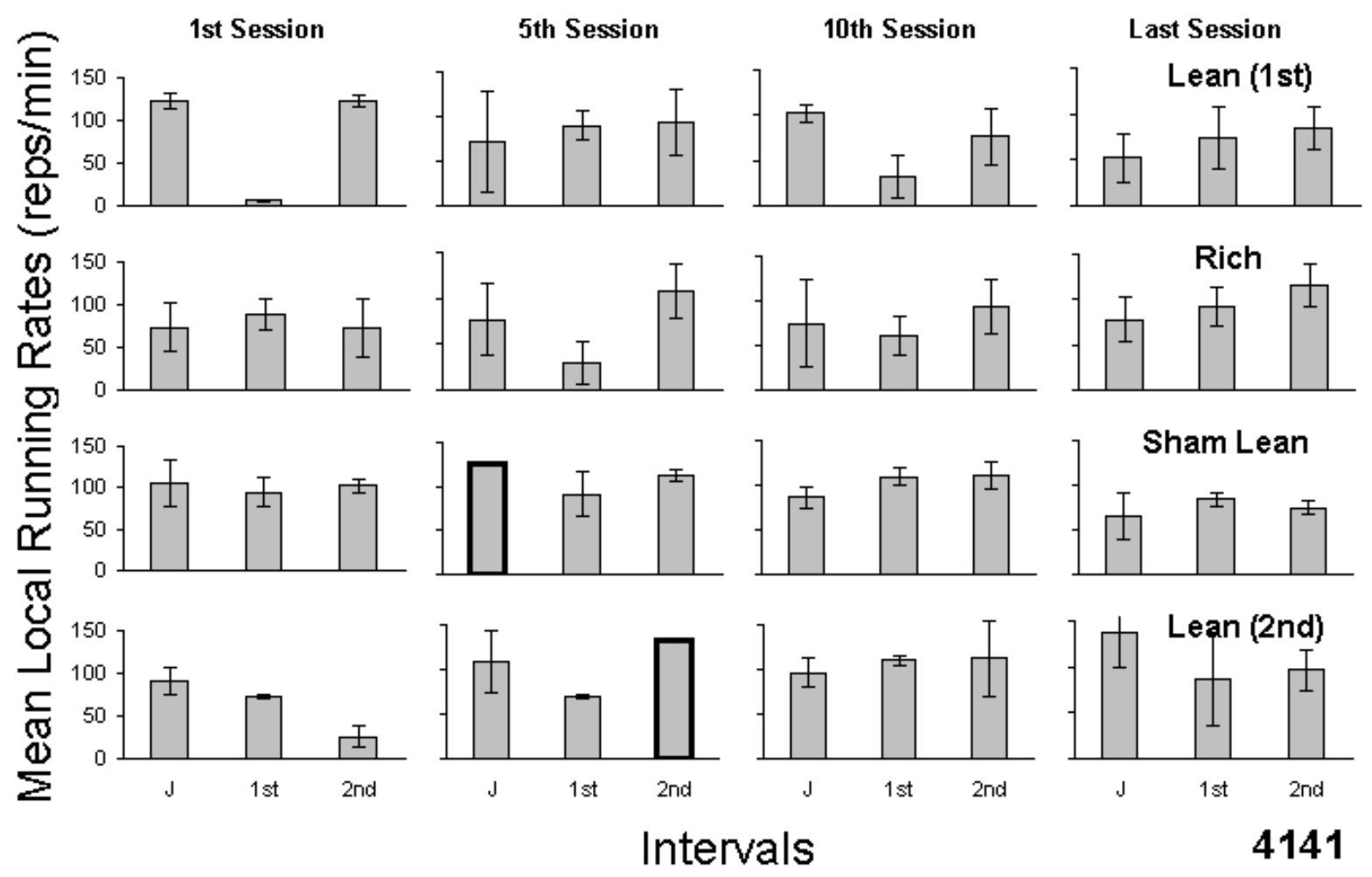

Figure 5c. Mean local running rate during the first, fifth, tenth, and last sessions of each experimental condition for P4141. "J," "1st," and "2nd" indicate intervals terminating with jackpot delivery and the first and second subsequent intervals after the delivery, respectively. A bolded border around the bar indicates that the value from at least one interval was excluded from calculation for having a post-reinforcement pause of greater than 60 -s. Error bars show a range of \pm 1 standard deviation 


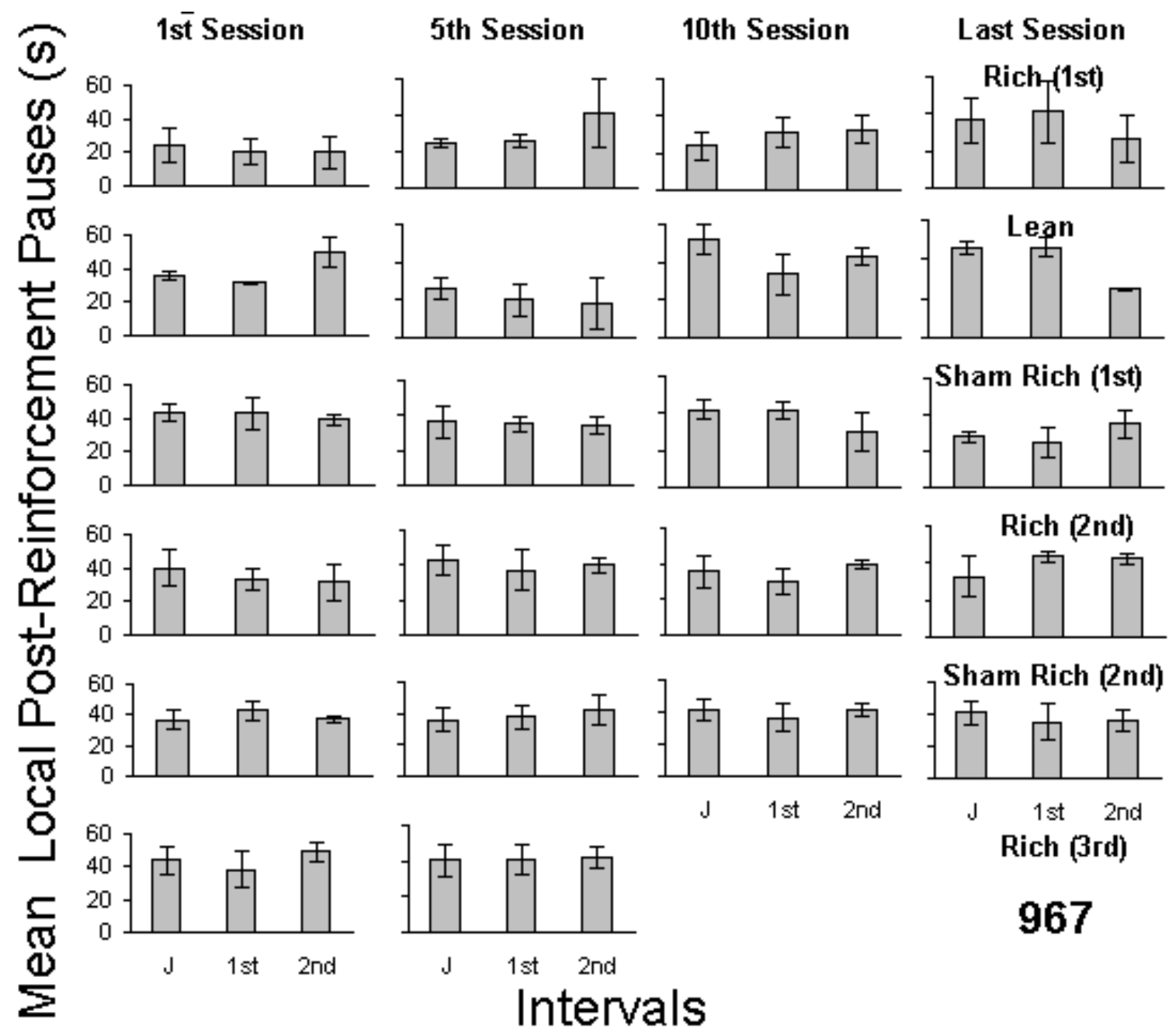

Figure 6a. Mean local post-reinforcement pause during the first, fifth, tenth, and last sessions of each experimental condition for P967. "J," "1st," and "2nd" indicate intervals terminating with jackpot delivery and the first and second subsequent intervals after the delivery, respectively. Error bars show a range of \pm 1 standard deviation 


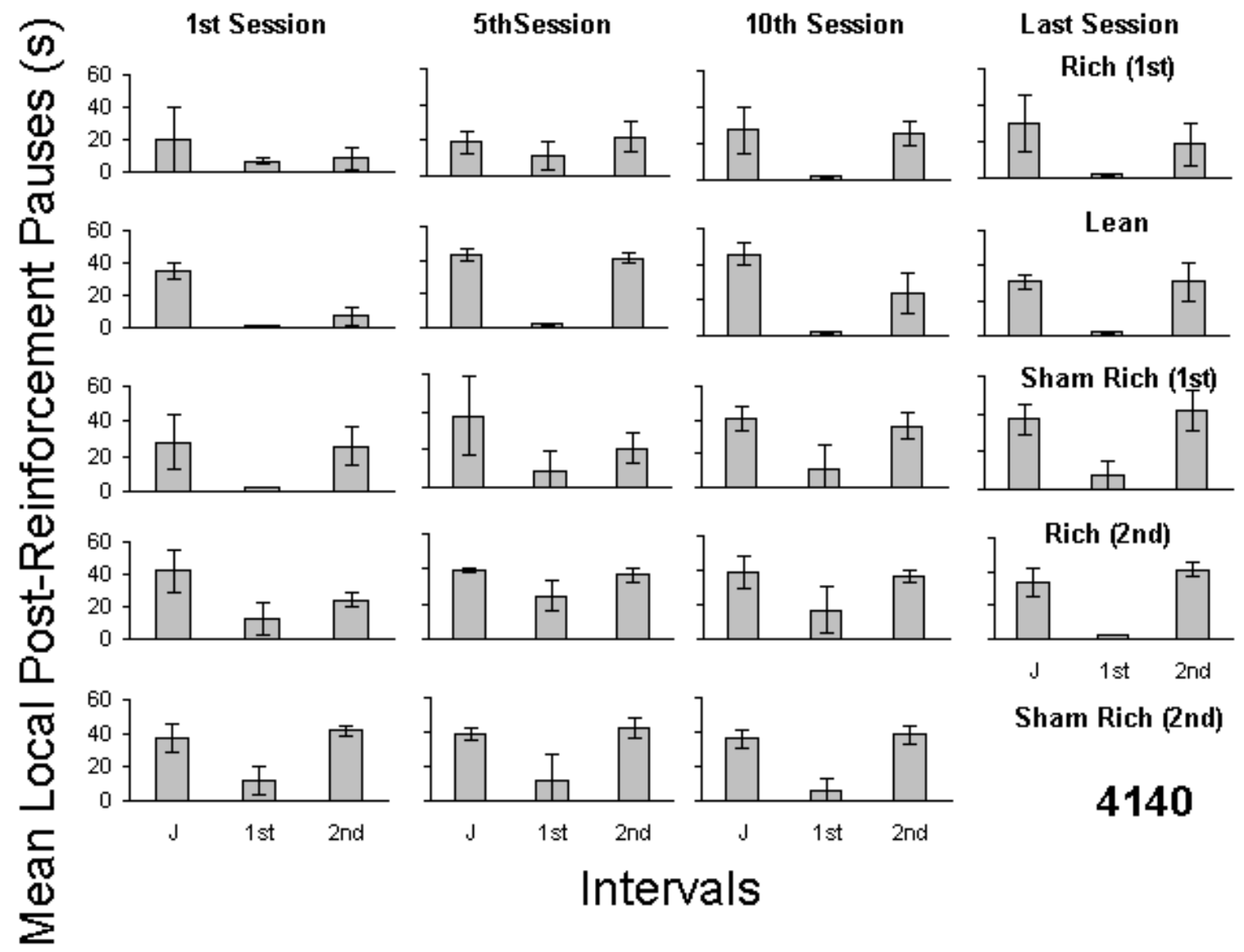

Figure 6b. Mean local post-reinforcement pause during the first, fifth, tenth, and last sessions of each experimental condition for P4140. "J," "1st," and "2nd" indicate intervals terminating with jackpot delivery and the first and second subsequent intervals after the delivery, respectively. Error bars show a range of \pm 1 standard deviation 


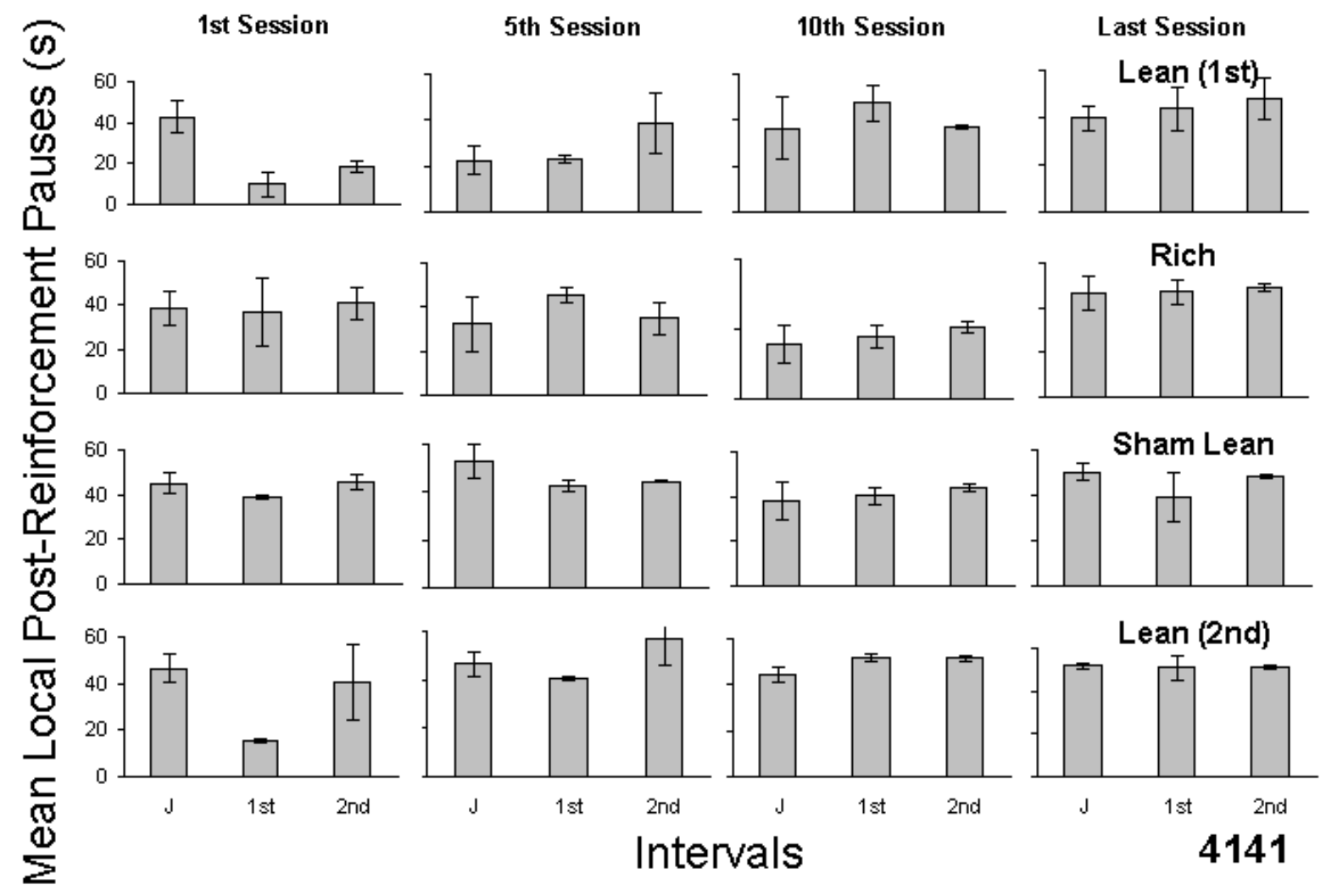

Figure 6c. Mean local post-reinforcement pause during the first, fifth, tenth, and last sessions of each experimental condition for P4141. "J," "1st," and "2nd" indicate intervals terminating with jackpot delivery and the first and second subsequent intervals after the delivery, respectively. Error bars show a range of \pm 1 standard deviation 


\section{Cumulative Response Distributions}

During the first baseline, responses cumulated in successive 5-s bins were analyzed across randomly selected 10 consecutive FI intervals within each session. Figure 7 shows a representative sample from the last session of the first baseline for each subject. This analysis showed two-state responding (i.e., the first state, pausing, followed by the second state, a constant rate of responding) in almost every FI interval (cf. Schneider, 1969). More importantly, response rates were similar once responding started despite differing PRPs. This in turn led to an analysis of responding across the FI that ended with a jackpot delivery (or a sham jackpot delivery) as well as the first and second subsequent intervals.

The analyses were conducted in two ways for each subject: Figure 8 shows changes in responding across successive jackpot deliveries during the first session of each experimental condition; Figure 9 shows changes across successive sessions (the first, fifth, tenth, and last sessions) of each condition by presenting responding across the FI terminating with the first jackpot that occurred during each of these sessions and the two successive FIs following that jackpot delivery. The first jackpot (or sham jackpot) delivery was selected for analysis in Figure 9 because it was assumed that the first delivery would be most "surprising" -a major characteristic of jackpotting (Pryor, 1984). It would be difficult to measure how surprised a subject was; it would be circular reasoning to infer that from the observation of behavioral effects of jackpotting. Procedurally, however, the first delivery could have acted as a signal for the high probability of subsequent jackpot deliveries within the session, thus, making them not so surprising.

The first delivery of jackpot (left top) suppressed FI responding for P967 and P4141 (see Figure 8a and 8c, respectively). A similar effect was observed in FI responding after the 
second jackpot delivery in the first Lean condition for P4141. Although the effect was not observed for the first three deliveries in the Rich condition in P4140, the fourth delivery suppressed the subsequent FI responding (see Figure 8b). Figures 9a-c show that effects of jackpotting on FI responding tended to disappear for each pigeon as sessions elapsed, with a few occasional exceptions (e.g., the tenth session of the first Lean condition with P4141). 


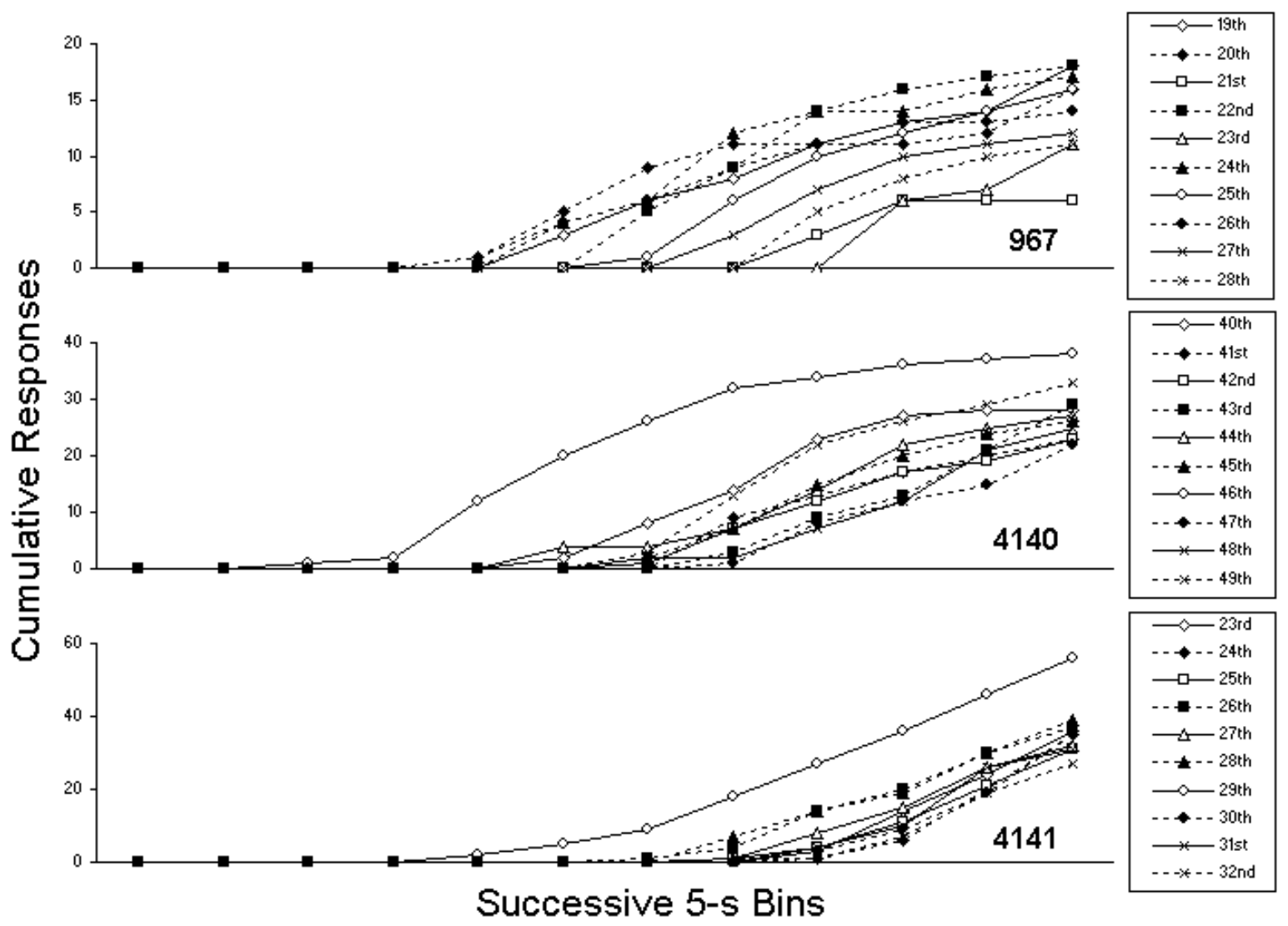

Figure 7. Cumulative responses in successive 5-s bins for randomly selected 10 consecutive FIs during the last session of the first baseline. Each legend shows a sequence of FIs for the indicated subject 


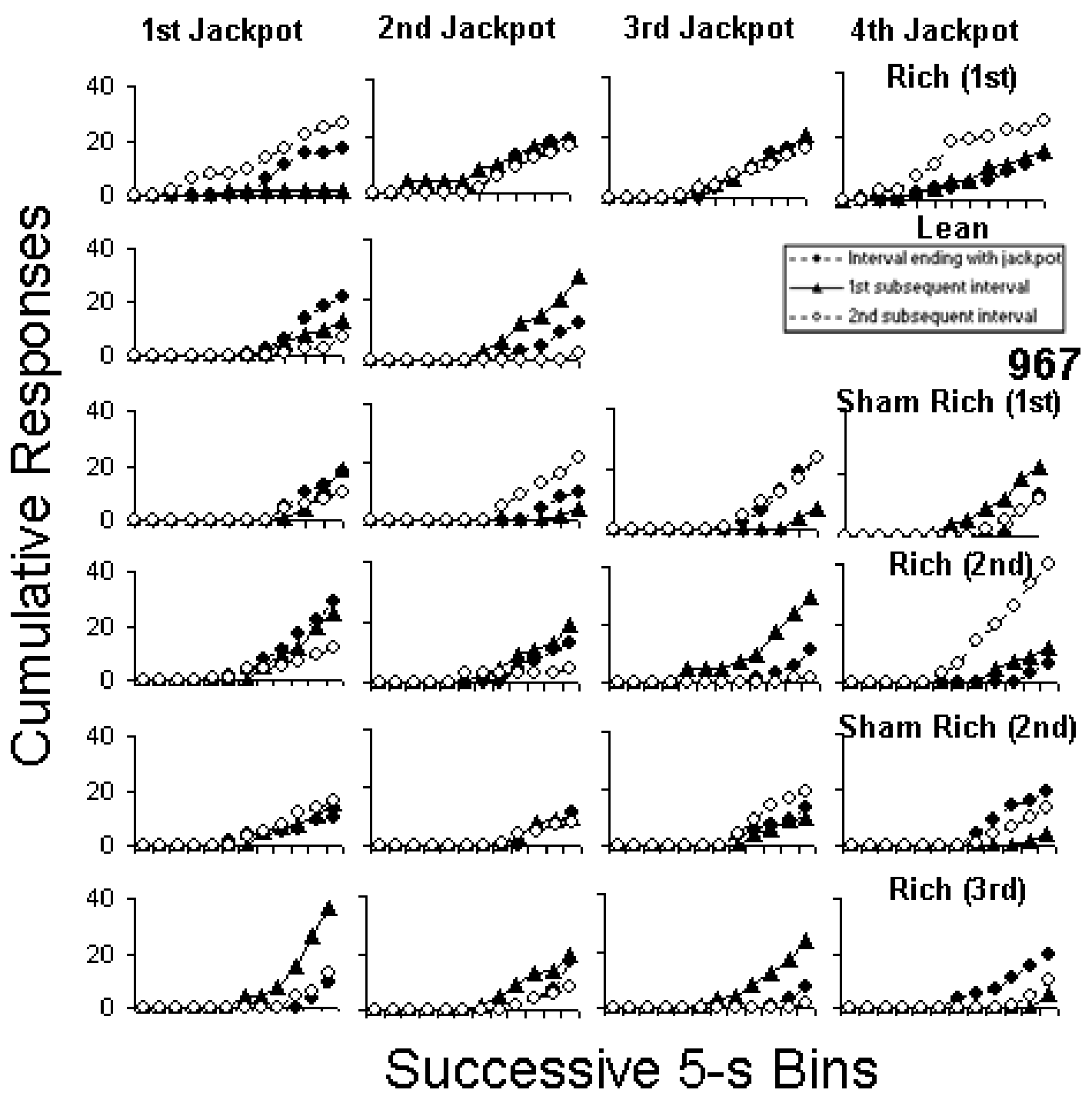

Figure 8a. Cumulative responses in successive 5-s bins across successive jackpot deliveries during the first session of each experimental condition for P967. An arrow indicates that the first subsequent FI also ended with a jackpot delivery 


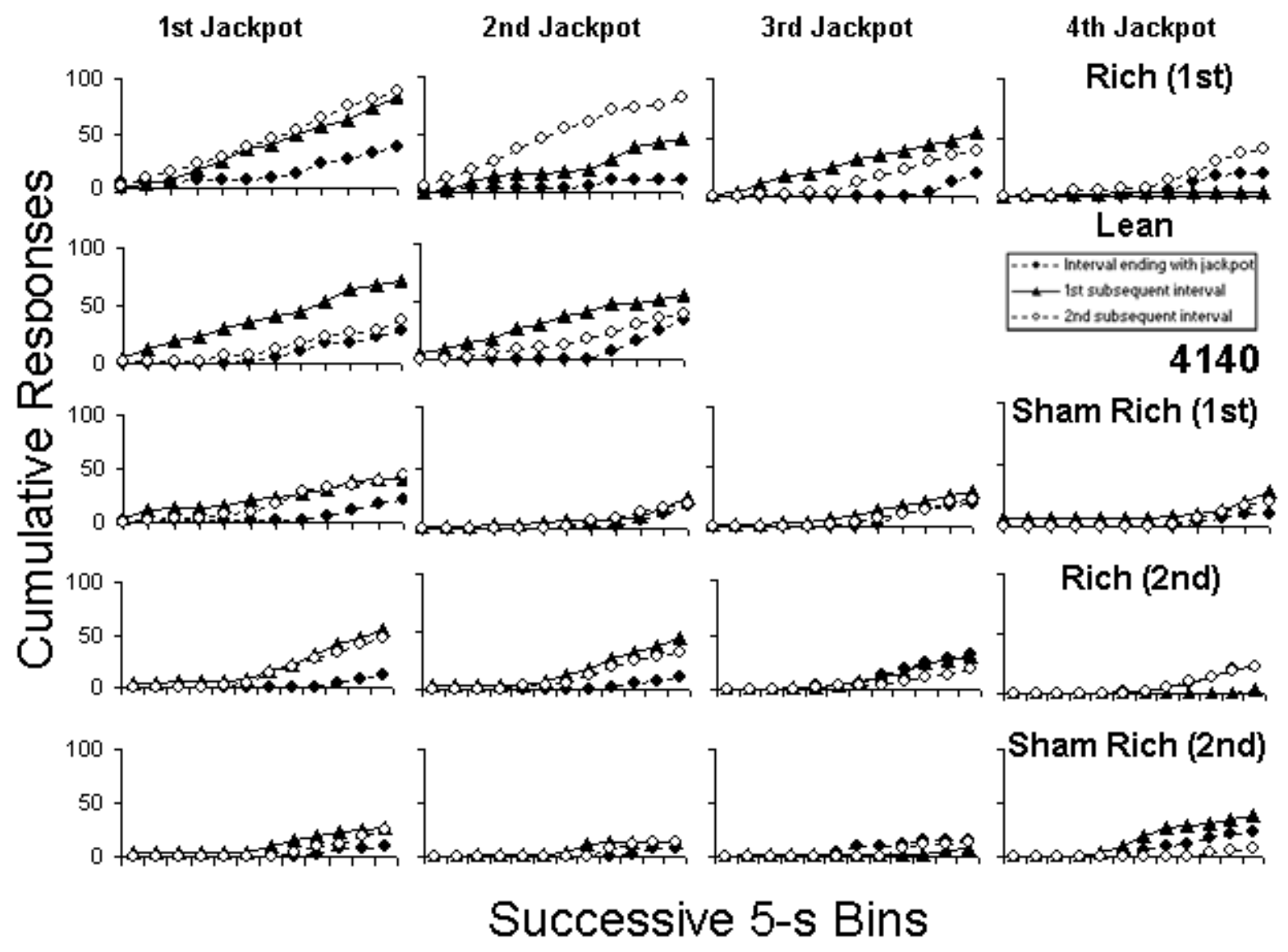

Figure 8b. Cumulative responses in successive 5-s bins across successive jackpot deliveries during the first session of each experimental condition for P4140. An arrow indicates that the first subsequent FI also ended with a jackpot delivery 


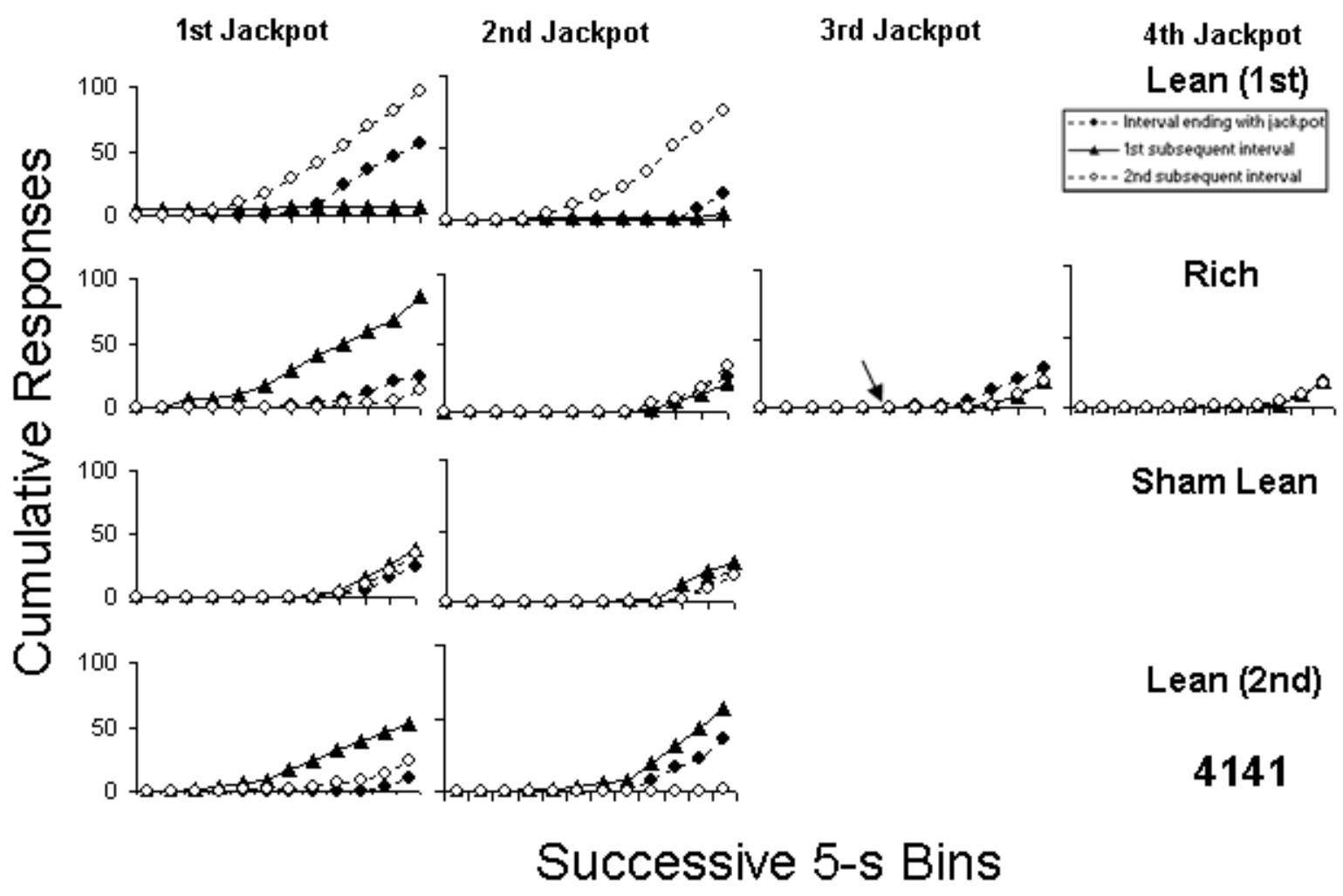

Figure 8c. Cumulative responses in successive 5-s bins across successive jackpot deliveries during the first session of each experimental condition for P4141. An arrow indicates that the first subsequent FI also ended with a jackpot delivery 


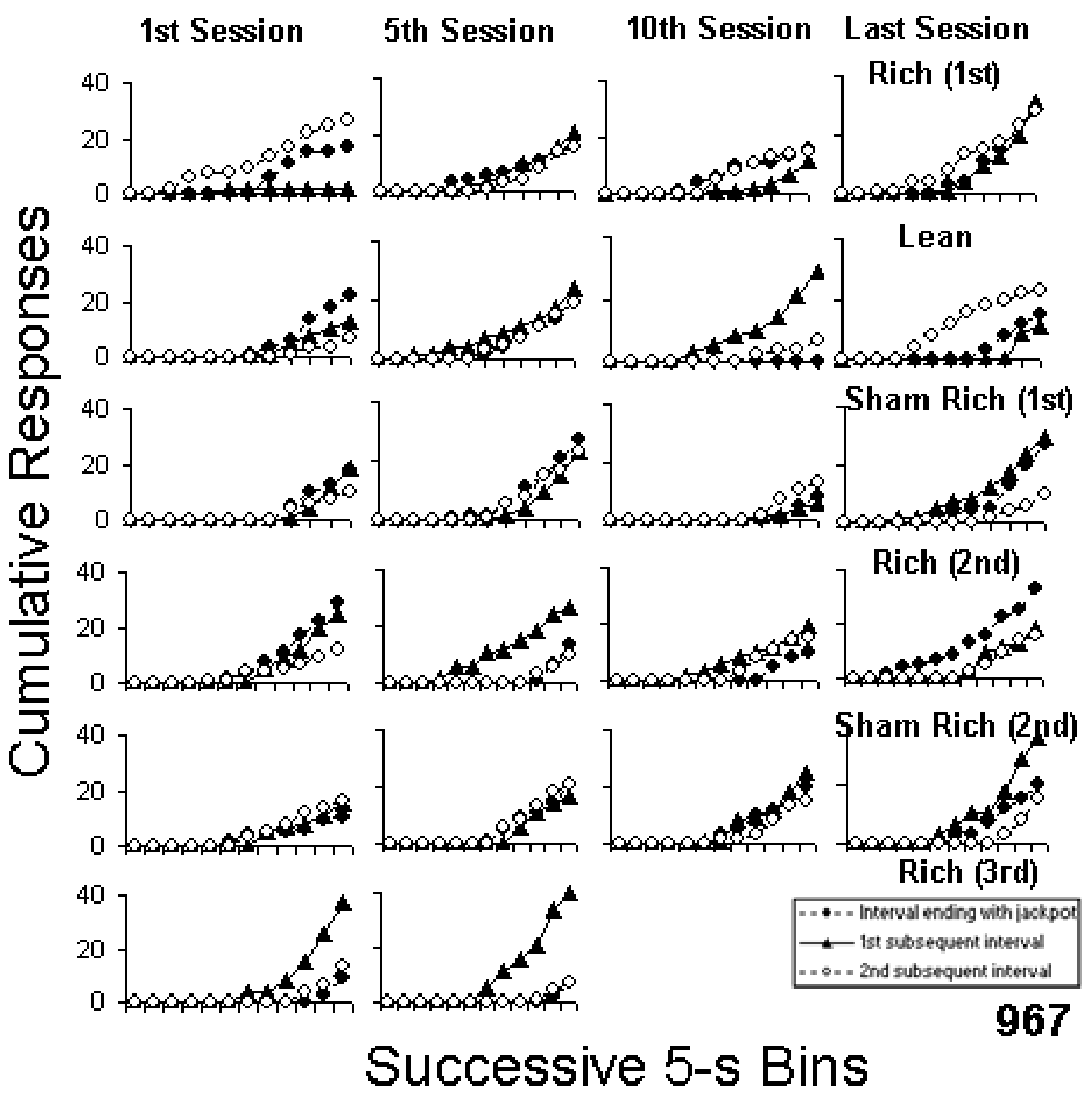

Figure 9a. Cumulative responses in successive 5-s bins across the FI terminating with the first jackpot that occurred during each of these sessions and the two successive FIs following that jackpot delivery during the first, fifth, tenth, and last sessions of each experimental condition for P967. An arrow indicates that the first subsequent FI also ended with a jackpot delivery 


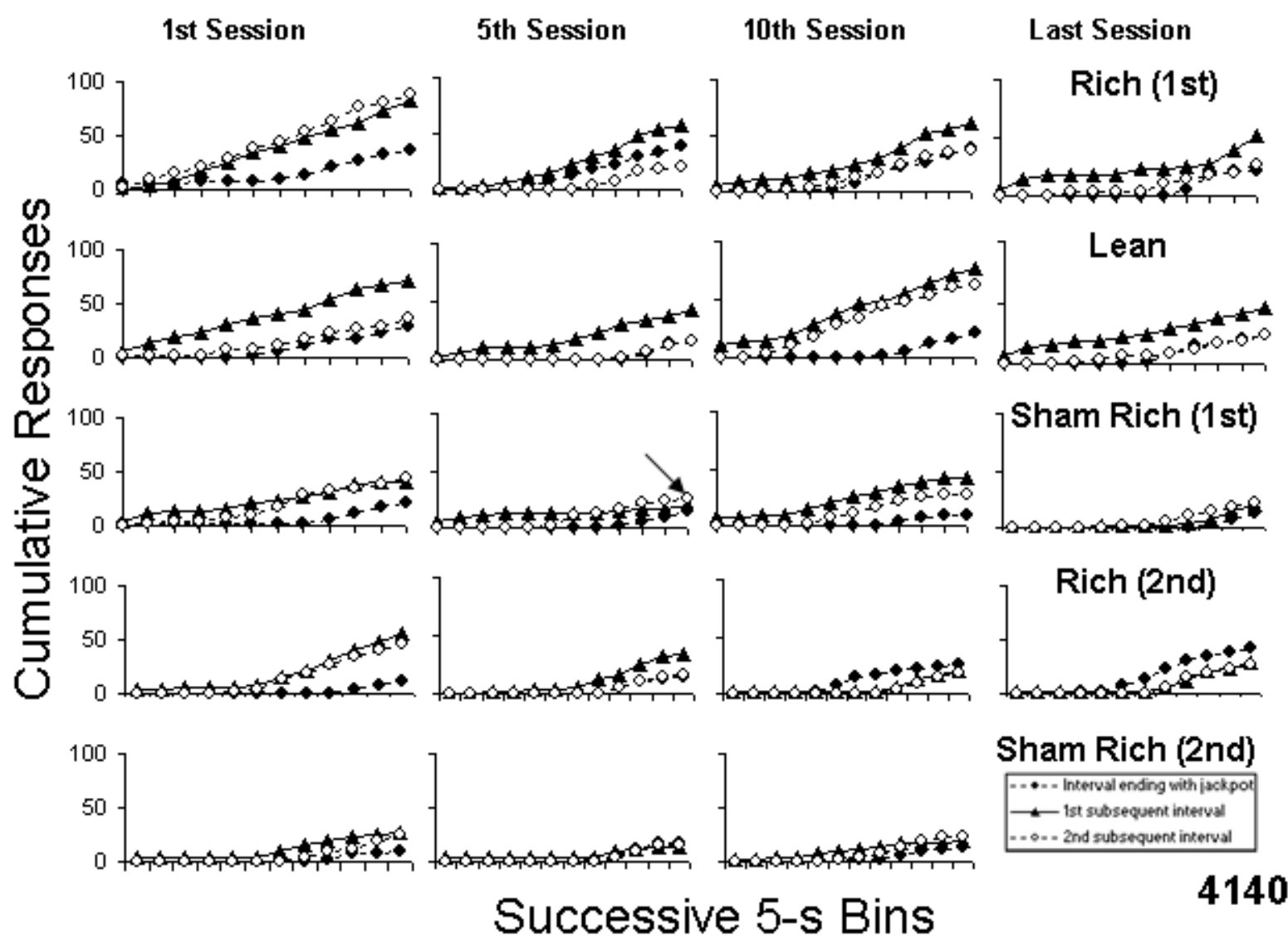

Figure 9b. Cumulative responses in successive 5-s bins across the FI terminating with the first jackpot that occurred during each of these sessions and the two successive FIs following that jackpot delivery during the first, fifth, tenth, and last sessions of each experimental condition for P4140. An arrow indicates that the first subsequent FI also ended with a jackpot delivery 


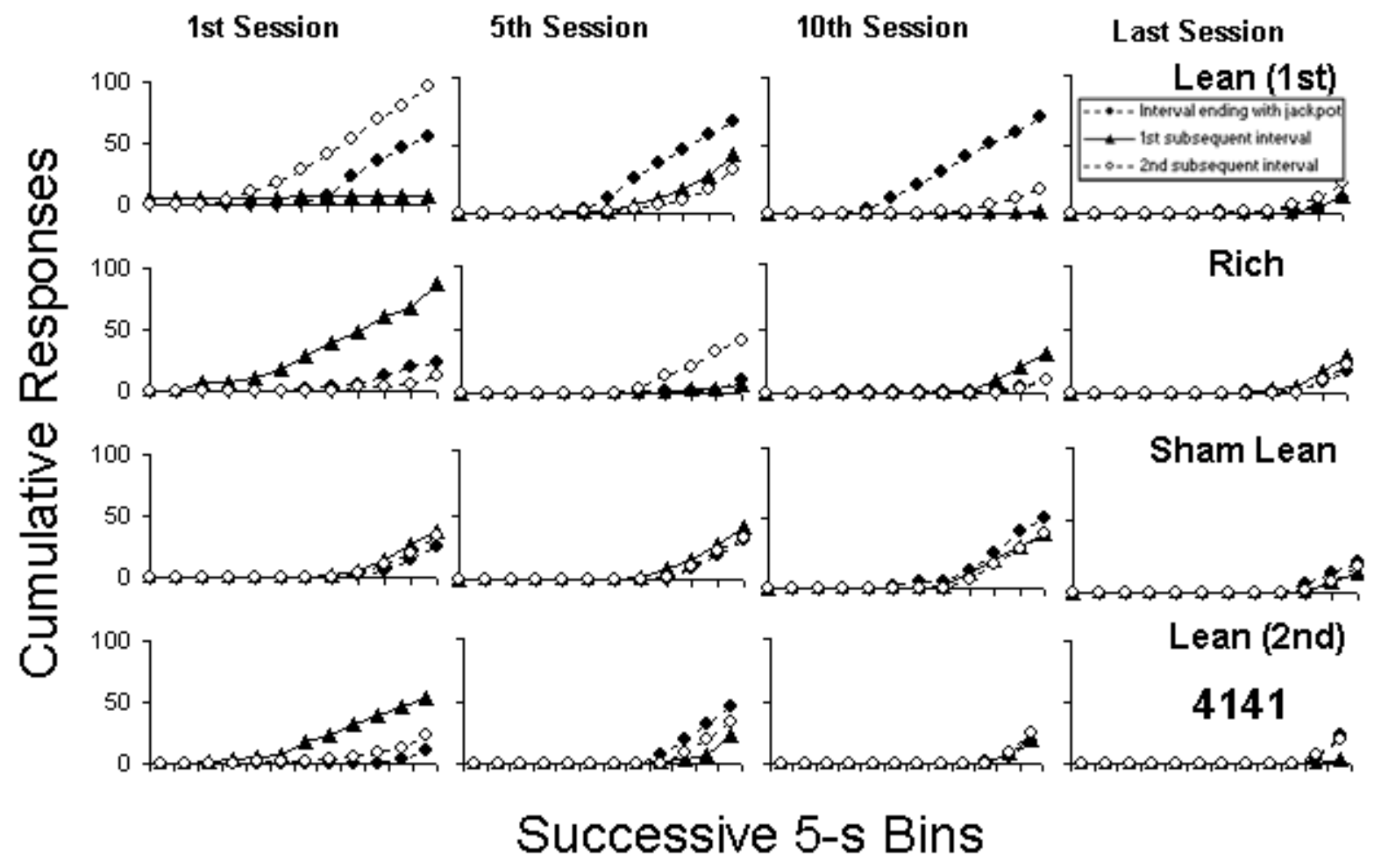

Figure 9c. Cumulative responses in successive 5-s bins across the FI terminating with the first jackpot that occurred during each of these sessions and the two successive FIs following that jackpot delivery during the first, fifth, tenth, and last sessions of each experimental condition for P4141. An arrow indicates that the first subsequent FI also ended with a jackpot delivery 


\section{Photocell Breakings}

Given the fact that jackpotting suppressed subsequent key pecking immediately after the delivery of jackpot at least for a short-term, the next question was, "What were the pigeons doing when not key pecking?" Event records as well as the monitor screen showed that pigeons were inserting their heads into the back hopper aperture during some FI intervals. Hopperchecking was operationally defined as a pigeon breaking the photocell beam across the magazine aperture with its head. Hereafter, the term refers specifically to the photocell breaking that occurred any time during FI intervals (but not during reinforcement), excluding the ones occurred within 3-s after hopper deactivation. Analyses of hopper-checking were conducted both across sessions (Figure 10) and across successive FI intervals during the first session of each experimental condition (Figure 11). The first sessions in which no back hopperchecking was recorded were excluded from the analyses in Figure 11.

\section{Across Sessions}

Figures 10a-c show the number of FI intervals in which hopper-checking occurred during all sessions of the experiment. P967 and P4140 showed an increase in the number for the back hopper in the first Rich and Lean conditions. The increase was also observed in the first Sham Rich condition. This suggests the possibility that the increases observed in the jackpot conditions may have been attributed to the food deliveries from the back hopper and/or the use of different color in magazine light rather than jackpotting per se. This interpretation, however, is unlikely: The increase in the number of back hopper-checking was observed in a direct transition from the second Sham Rich to the third Rich condition for P967 (see Figure 10a) as well as from the first Sham Rich to the second Rich condition for P4140 (see Figure 10b). Because everything but the reinforcer magnitude was held constant, the increase is likely to be attributed to jackpotting per se. 
Unlike the other two pigeons, P4141 seldom showed an increase in the frequency although the back hopper-checking was observed once in the first condition of the first jackpot condition. This suggests that hopper-checking behavior does not happen to some animals. Across Successive FI intervals

Figures 11a-c show the number of back hopper checks that occurred within an interval across successive FI intervals. P967 showed the behavior immediately after the delivery of jackpot and the behavior frequently recurred during a few subsequent FI intervals. A similar effect was observed in the sham jackpot conditions with the pigeon.

Unlike P967, there were delayed occurrences of back hopper-checking after the deliveries of jackpot and of sham jackpot with P4140. As noted above, P4141 showed little increase in back hopper-checking but it did increase immediately after the second jackpot during the first session of the first Lean condition. 


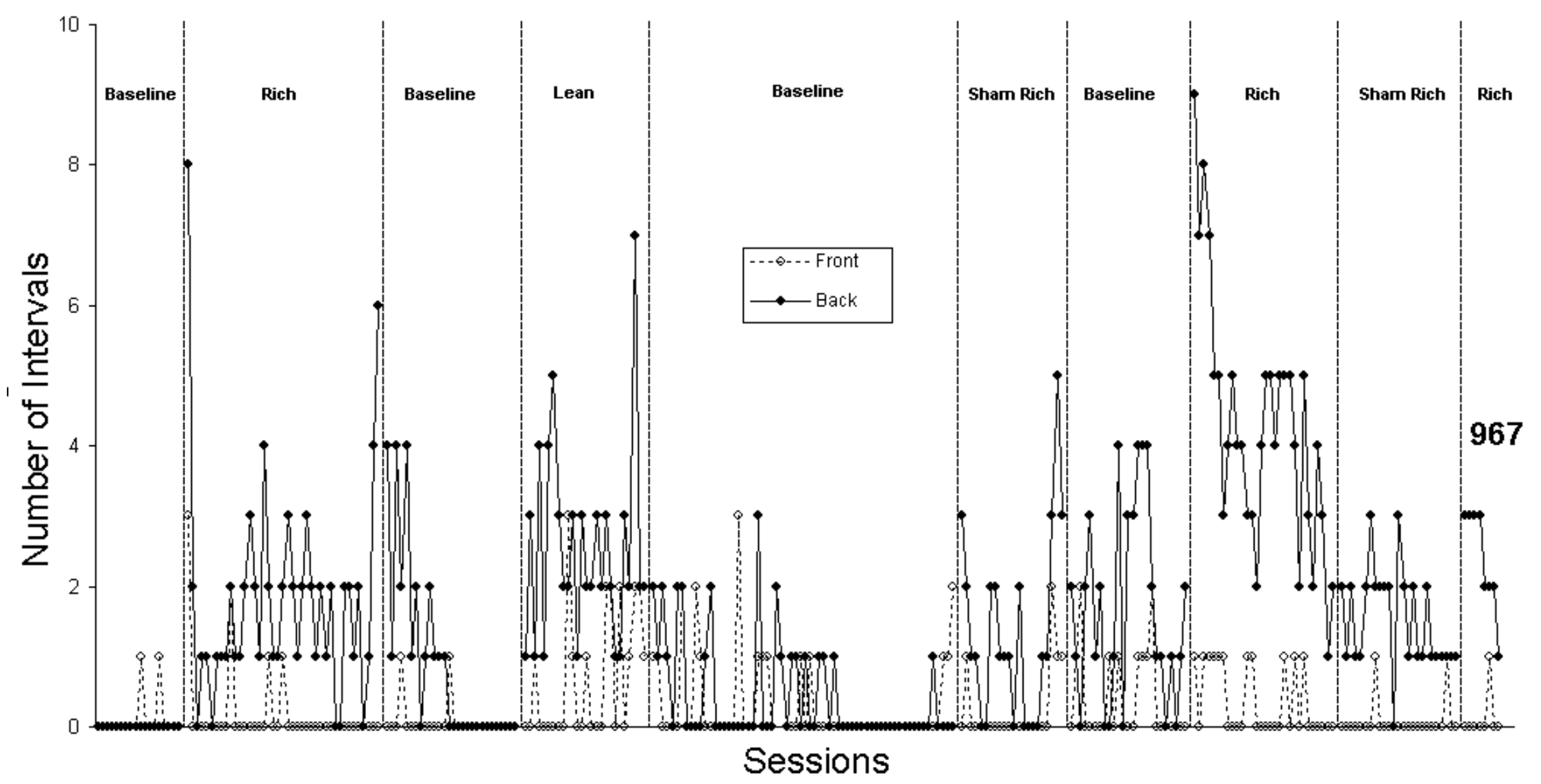

Figure 10a. The number of intervals in which hopper-checking occurred at least once as a function of successive sessions for P967 


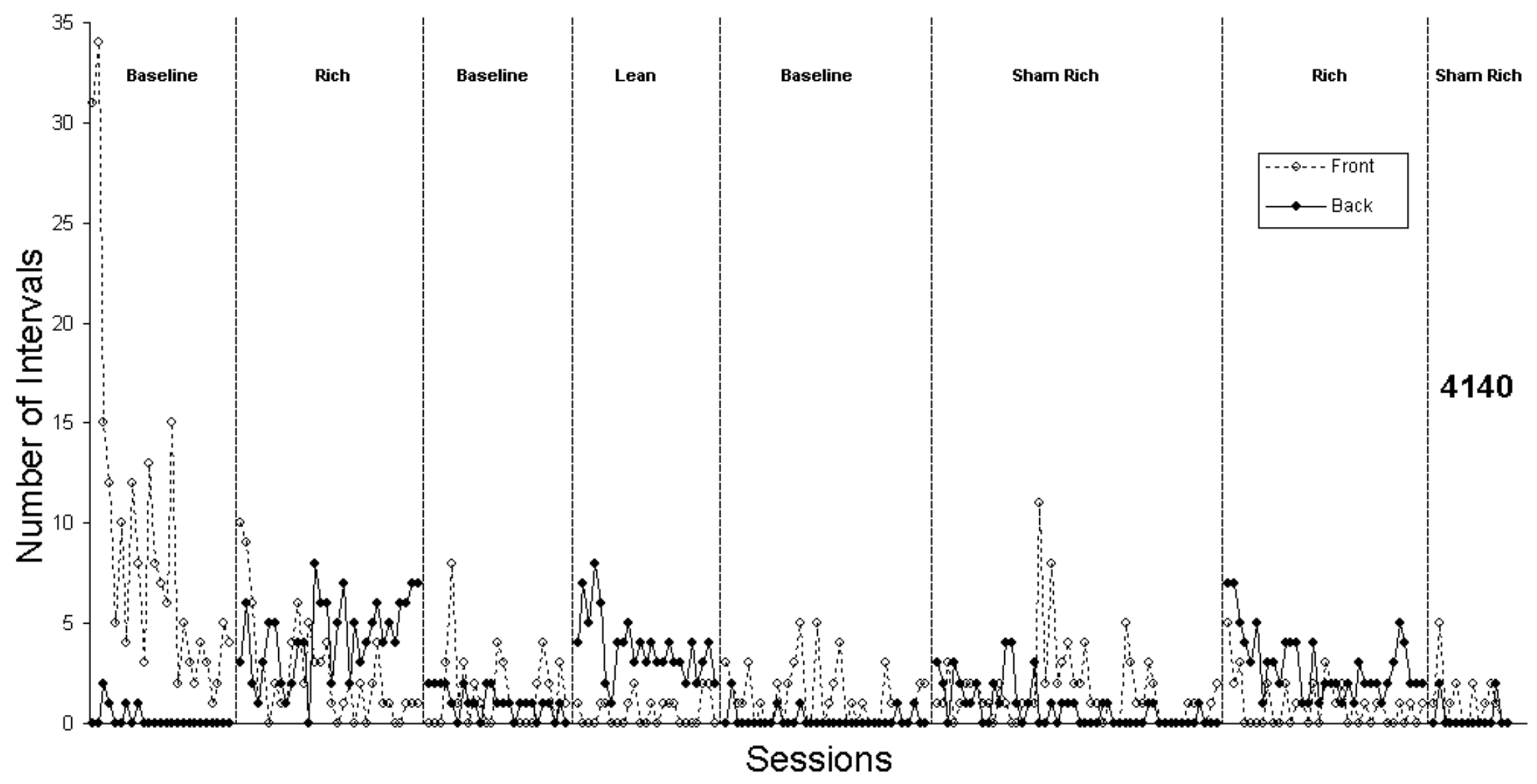

Figure 10b. The number of intervals in which hopper-checking occurred at least once as a function of successive sessions for P4140 


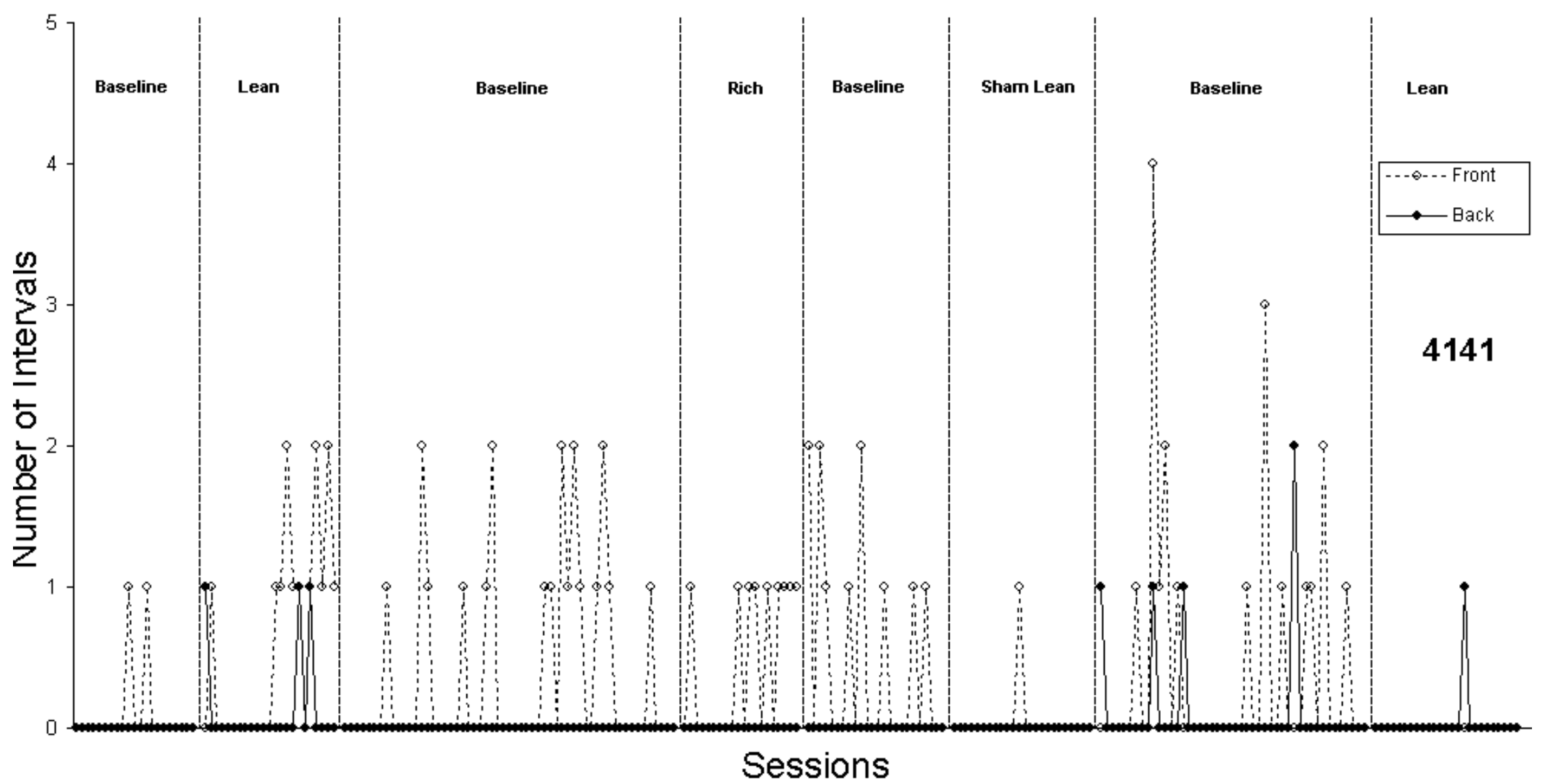

Figure 10c. The number of intervals in which hopper-checking occurred at least once as a function of successive sessions for P4141 


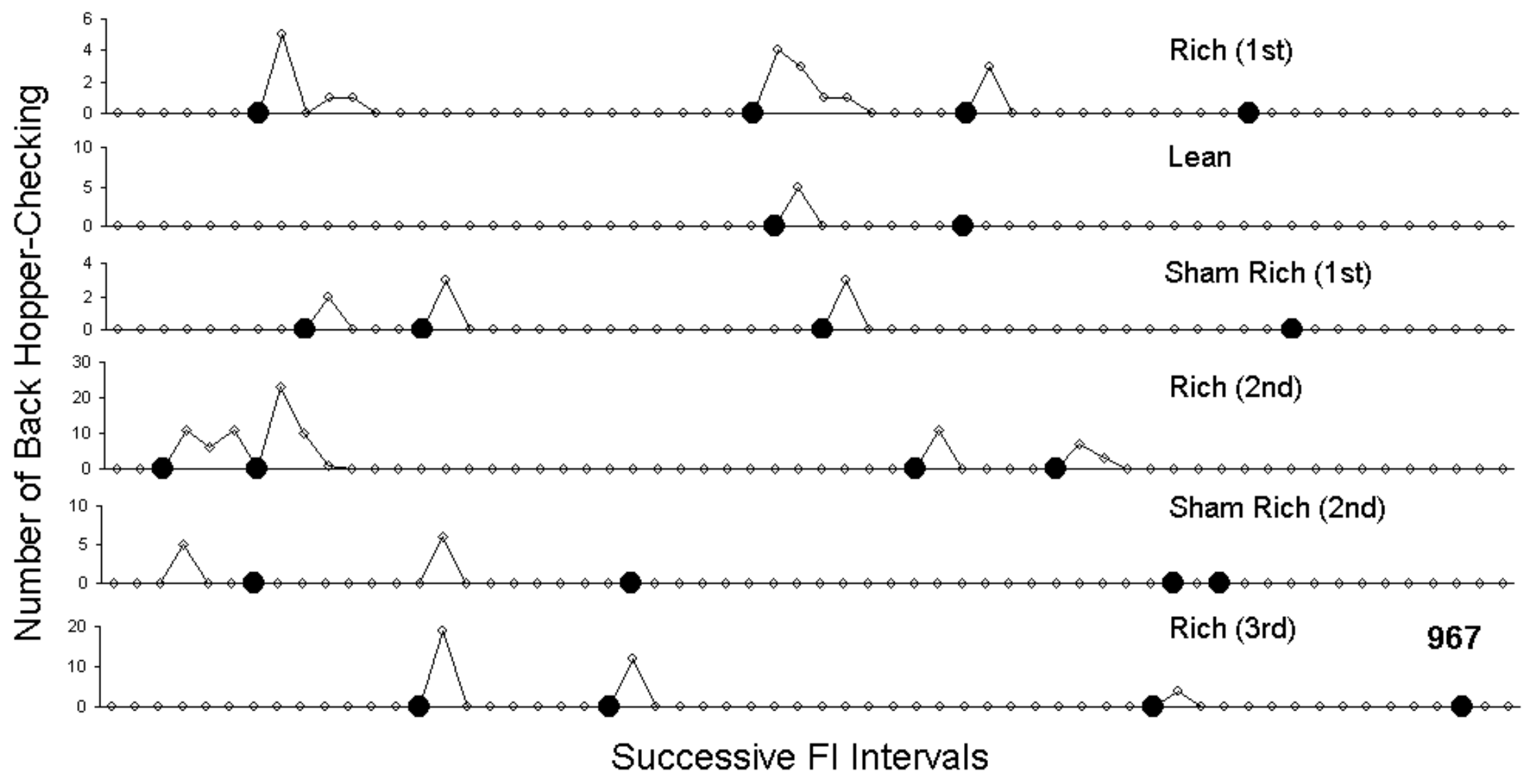

Figure 11a. The number of back hopper-checking that occurred within an interval as a function of successive sessions for P967 


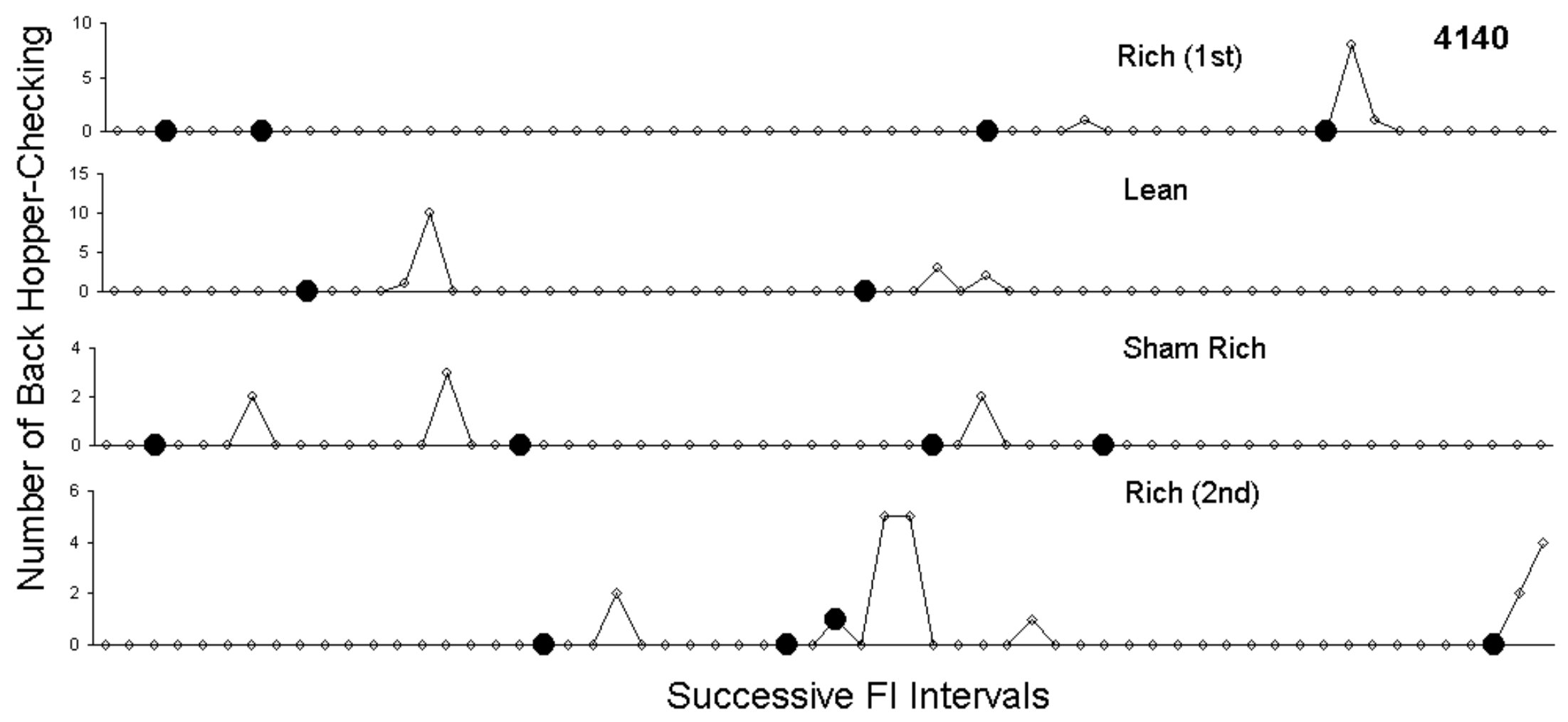

Figure $11 b$. The number of back hopper-checking that occurred within an interval as a function of successive sessions for P4140 


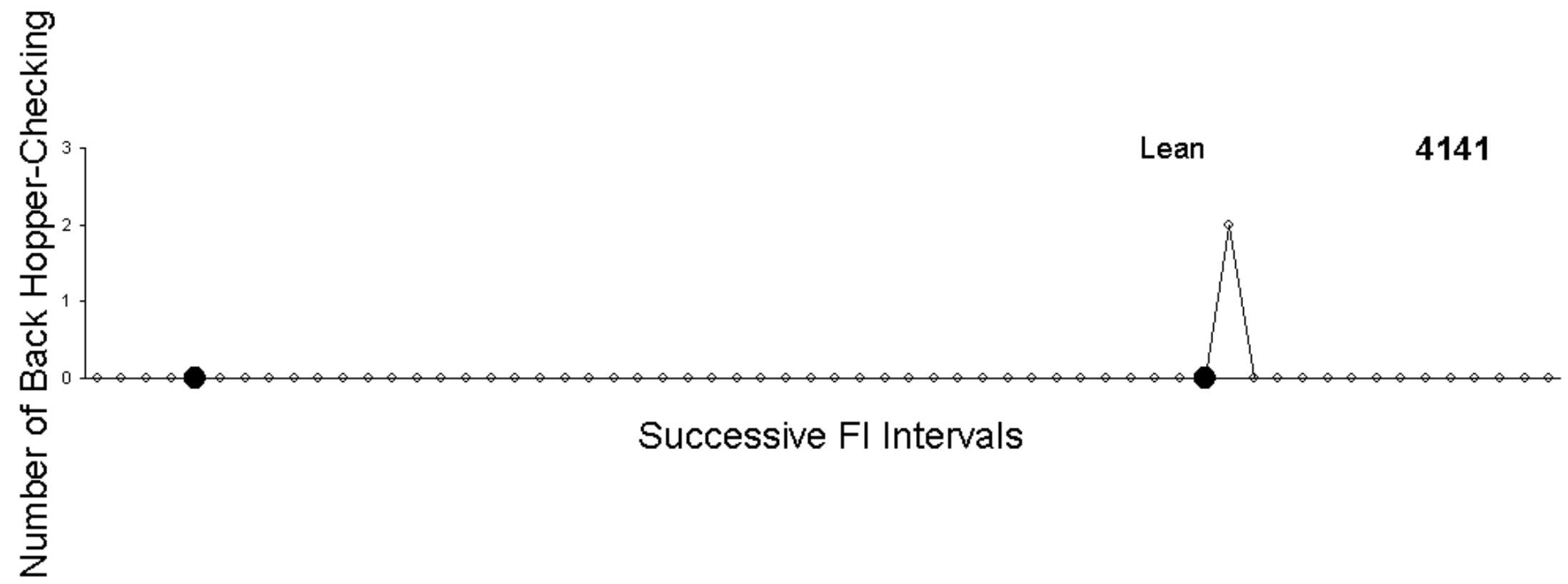

Figure 11c. The number of back hopper-checking that occurred within an interval as a function of successive sessions for 4141 


\section{Discussion}

Jackpotting has been described in the animal training literature as having a disproportionally strong reinforcing effect on responding. In the present experiment, effects of response-dependent jackpotting were examined with a variety of measures using an FI schedule. There was no clear effect of such a jackpotting effect on global measures (i.e., response rates, running rates, and mean PRPs). The only consistent effect in two of three pigeon was that the shortest mean PRPs were observed during the first session of the first experimental condition with jackpot delivery. The results of the sham control conditions, however, suggest that this effect is attributable to the use of the back hopper and/or of different color in magazine light rather than jackpotting per se. Analyses of cumulative response distributions suggest that jackpotting may have a short-term suppressive effect on FI responding. Thus, the results of the present experiment appear to be inconsistent with the description of jackpotting in the animal training literature. Moreover, it appears that the total number of jackpots delivered within a session does not have a differential effect, at least within the range studied herein. There was, however, one consistent finding across pigeons: Back hopper-checking increased as a result of the delivery of jackpot reinforcers. These results are discussed below in terms of each topic developed in the literature review of this thesis.

\section{Reinforcer Magnitude Per Se}

The present findings are consistent with previous experiments dealing with reinforcer magnitude in the sense that the magnitude is not a reliable independent variable (Bonem \& Crossman, 1988). In particular, these authors pointed out that the effect of reinforcer magnitude is not reliably observed when imposed simple reinforcement schedules. The present experiment used a simple FI schedule as an initial step to examine effects of jackpotting. Its use may have 
obscured the effects, if any. Perhaps another procedure would have revealed a clear effect of jackpotting on responding. For example, Catania (1963) showed that a concurrent schedule was a more sensitive procedure for assessing differential reinforcer magnitudes. Likewise, changes in responding by jackpotting may be measured more sensitively with concurrent schedules than simple FI schedules.

\section{Changes in Magnitude}

\section{Incentive Contrast}

Previous studies have shown that the chronic increase in reinforcer magnitude leads to a positive incentive contrast (overshooting): The performance of animals experiencing a magnitude change from small to large exceeds the responding maintained by a large magnitude from the start (e.g., Crespi, 1942). In contrast, jackpotting has been described as an abrupt, momentary increase in the magnitude. Because there was no comparison (e.g., a condition whereby all delivered reinforcers are jackpots) in the present procedure, it was not possible to assess whether such an overshooting occurs with jackpot reinforcers. Moreover, jackpot delivery, especially, that took place in the early part of the experiment suppressed rather than facilitated FI responding that immediately followed the delivery. With an appropriate procedure for incentive contrast, it is possible to determine whether the suppressed responding results from the abrupt decrease in reinforcer magnitude immediately after jackpotting (i.e., undershooting).

Despite the difficulty in comparing the present experiment with the incentive contrast literature, the observed diminished effect of repeated jackpotting appears similar to that exposure to varied reinforcer magnitudes reduces the degree of incentive contrast (Flaherty, 1982). Procedurally, pigeons were experiencing varied reinforcer magnitudes in the present 
experiment (i.e., 1-s and 7-s reinforcers). In this sense, effects of jackpotting may share a common element with incentive contrast. The procedural similarity, however, is not a sufficient condition to argue that the two follow a common behavioral process. Perhaps, mechanisms for the lower degrees of effect are different between incentive contrast and jackpotting. For example, the attenuated incentive contrast may be attributed to the exposure to varied magnitudes of reinforcer whereas the attenuated effects of jackpotting may result from repeated exposures to a high magnitude.

\section{Reinforcement Omission and Reinforcement Commission}

Jackpotting may be viewed as the inverse of reinforcement omission - commissionin the sense that the directions of change in reinforcement magnitude are the opposite. Staddon (1972) showed that reinforcement omission resulted in an increase in responding on a tandem DRO VI schedule ("No-Go-Go"). The schedule is procedurally similar to an FI schedule used in the present study because, with extended exposures, both of the schedules can produce a break-and-run pattern of responding (cf. Schneider, 1969). The decrease in responding by jackpotting thus seems consistent with the idea that it is the inverse of reinforcement omission.

Kello (1972) showed that the effect of reinforcement omission was an inverse function of the physical similarity between the omission condition and the reinforcement condition. In the present experiment, it was attempted to increase discriminability of jackpotting from the standard reinforcement (1) by using a seven-fold difference in reinforcement cycles, (2) by using different colors (white and green) of feeder lights associated with each type of reinforcer, and 3) by using two hoppers, each in a different physical location in the chamber. In particular, the latter two were an attempt to allow the pigeons to immediately contact with a different type of reinforcement (i.e., jackpotting). These same features, however, also were potential 
confounds in the observed effects of jackpotting. It was attempted to removed these potential confounds by changing the condition from the Sham Rich to the Rich with two subjects. By the time this attempt was implemented, however, the decrease in responding by jackpotting disappeared. Thus, the answer to the question of whether jackpotting per se suppresses FI responding remains elusive.

Surprise

Kamin (1969) as well as Rescorla and Wagner (1972) argued that learning in Pavlovian conditioning results from some unexpected feature in the US event in the presence of CS. In the present experiment, pigeons encountered a jackpot never experienced before in the first session of the first experiment (thus, presumably it was an "unexpected" event if borrowed a cognitive terminology). Thus, it is possible that Pavlovian conditioning took place in some aspect of behavior as a result of jackpotting. One possibility is back hopper-checking that followed jackpot delivery. Assuming that food is the US, consummatory response is the UR, and the back hopper is the CS (neutral stimulus initially), the "unexpected" jackpot delivery may have yielded a CR (i.e., consummatory response in the back hopper).

It also seems possible to argue that the effect on back hopper-checking resulted from operant contingencies. Specifically, the behavior that preceded obtaining a jackpot was sticking the head in the back hopper aperture. Because the contact with a jackpot was temporally closer to this response than key-pecking, the former response might have been superstitiously reinforced, assuming an additional reinforcing effect in jackpotting. In this way, hopperchecking behavior may have competed with key-pecking, which is consistent with the suppressed FI responding observed after jackpot deliveries. Along the same line, it might be interpreted that the diminished effect observed in a few subsequent FI intervals as well as in 
subsequent jackpotting resulted from operant extinction; that is, hopper-checking did not have any consequence.

\section{Response Reinstatement}

A peculiar feature of back hopper-checking is that the behavior was also observed in Sham conditions, although its frequencies were relatively lower. This might be explained by the discriminative property of the reinforcer. Specifically, it has been argued that a reinforcer plays at least two roles in maintaining behavior: It functions to strengthen behavior and also as a discriminative stimulus (e.g., Jenkins, 1965) evoking previously reinforced behavior. If the stimuli during sham jackpot presentations (i.e., the back hopper with a green feeder light, but without the food delivery) acted as a discriminative stimulus, it is possible that the stimulus resulted in back hopper-checking in a similar sense to response reinstatement.

In typical reinstatement experiments, responding is first maintained by some responsedependent schedule of reinforcement. After the responding is extinguished under extinction, a reinforcer is delivered using a response-independent schedule such as a FT schedule (e.g., Franks \& Lattal, 1976) or delivered using a DRO schedule (e.g., Campbell, Phillips, Fixsen, \& Crumbaugh, 1968). A typical result is that responding comes back immediately after a reinforcer delivery (Reid, 1958). Furthermore, Franks and Lattal (1976) showed that the reinstated responding is similar to that previously reinforced: Reinstated response rates were high if a VR schedule was used and low if a differential-reinforcement-of-low-rate (DRL) schedule was used.

More importantly, Pryor's description of response-independent jackpotting (1984, p. 32) suggests that the jackpot effect may be related to response reinstatement. These two, indeed, share common elements. First, both may involve the delivery of reinforcers 
independently of responding. Campbell et al. (1968) noted that it is counterintuitive that the delivery of reinforcers according to DRO schedules increase rather than decrease a target behavior, as in Pryor's description of response-independent jackpotting. Second, neither effect appears to last long. Burch and Bailey (1999) mentioned the possibility of diminished effect due to its overuse of jackpots and Pryor emphasized that "it's necessarily a rare than a repeated event" (personal communication, August 28, 2008). Similarly, in response reinstatement, further deliveries of response-independent food decreased responding (e.g., Franks \& Lattal, 1976).

A next logical step is to examine the effects of differential reinforcer magnitude (normal reinforcer vs. jackpot) by using a response reinstatement procedure. Campbell, Fixsen, and Phillips (1969) conducted such an experiment. After training four groups of rats on a runway in which the goal box had five food pellets, all the groups were placed on extinction. Then once a day for four days, the rats were placed directly in the goal box containing a different number of food pellets for the different groups $(0,5,10$, or 20$)$ independently of responding. Following the exposure to the response-independent food, their performance was tested once a day for six days under extinction. Running speed was generally higher for the group that received greater numbers of the response-independent food. This suggests that reinstated responding is likely to be higher after a response-independent jackpot delivery than with a response-independent normal reinforcer, being consistent with Pryor's (1984) description of response-independent jackpot delivery. There is, however, a seemingly important procedural different between the two cases: There was a one-day gap between the exposure to the response-independent food and the test condition in Campbell et al.'s (1969) experiment whereas there was little temporal separation in Pryor's description (1984). This 
variable may be considered in the future research. Furthermore, the results of Campbell et al.'s (1969) need to be considered with caution because the effects of jackpotting may depend on the type of response-dependent schedules of reinforcement used prior to extinction, as suggested in Franks and Lattal's (1976) experiment.

In short, it is possible that the disproportionally strong reinforcing effect that Pryor (1984) observed in jackpotting was an instance of response reinstatement. Besides the possible effect of a large reinforcer magnitude in response reinstatement, the behavioral effect of jackpotting may have been exaggerated because the psychological difference in responding, say, between a response rate of zero and one of 10 is bigger than between response rates of 10 and 20, as the application of Weber's law to these differences might suggest. .

\section{Conditioned Emotional Responses}

Research on conditioned emotional responses may be relevant to jackpotting, in particular, back hopper-checking observed in the present experiment. Conditioned anxiety was investigated by Estes and Skinner (1941). After pointing out that anxiety is often defined as a result of anticipating a future event, they argued that a current stimulus is responsible because a stimulus that has not taken place yet cannot cause behavior. They used a tone (CS) as a signal for electric shock (US) and demonstrated that the presentation of tone suppressed rats' responding, which they operationalize as anxiety.

It should be noted that, unlike Estes and Skinner's (1941) experiment, a CS did not signal the upcoming delivery of jackpot in the present study. Nonetheless, Schoenfeld (1950) extended the Estes and Skinner's conditioned emotional response paradigm to avoidance and escape models. One of the escape paradigms shares a common element with the hopperchecking behavior: 


$$
\mathrm{S}_{1} \rightarrow \mathrm{S}_{2} \cdot \mathrm{R}_{\mathrm{T}}
$$

where $\mathrm{S}_{1}$ and $\mathrm{S}_{2}$ are, a conditioned aversive stimulus and an aversive stimulus, respectively, while $\mathrm{R}_{\mathrm{T}}$ is a response which terminates the presentation of $\mathrm{S}_{2}$. In this paradigm, $\mathrm{R}_{\mathrm{T}}$ does not terminate $S_{1}$ and, therefore, a subject receives the aversive stimulus independently of responding. Nonetheless, Schoenfeld cited a study by Brogden, Lipman, and Culler (1938) in which a considerable number of $\mathrm{R}_{\mathrm{T}} \mathrm{S}$ was observed prior to the presentation of $\mathrm{S}_{2}$ (i.e., ineffective intervening responses between $\mathrm{S}_{1}$ and $\mathrm{S}_{2}$ ).

Similarly, it may be argued that a considerable number of hopper-checking (replacing $\left.\mathrm{R}_{\mathrm{T}}\right)$ occurred in the presence of the keylight and/or the back hopper $\left(\mathrm{S}_{1}\right)$ after the delivery of a jackpot $\left(\mathrm{S}_{2}\right)$ despite the fact that such behavior had no consequence in the present experiment. In other words, one effect of jackpotting may be to induce some non-operant behavior (e.g., hopper-checking) in a similar but opposite sense to the effect of electric shock. If so, it might be worth conducting a similar experiment to that of Estes and Skinner (1941), using a CS signaling an upcoming jackpot delivery.

\section{Conclusion}

Jackpotting has been described as having a disproportionally strong reinforcing effect on behavior in the animal training literature. The present experiment suggests that the delivery of response-dependent jackpots does not enhance FI responding of pigeons, either globally or locally. Rather, jackpotting typically suppressed the responding, contradictory to the description of jackpotting in the animal training literature. The suppressive effect, however, may be attributable to an increase in hopper-checking which competed with key pecking. If so, then the present findings do not necessarily contradict the animal training literature. Perhaps, the main effect of jackpotting is to reinforce the consummatory response. The discriminative 
property of food associated with the response may have reinstated behavior during the training of the dolphin described by Pryor (1984). It is suggested that in future experiments on jackpotting that the manipulation of other variables than reinforcer magnitude be considered, such as the discriminative stimuli or schedule of reinforcement. 


\section{References}

Bonem, M., \& Crossman, E. K. (1988). Elucidating the effects of reinforcement magnitude. Psychological Bulletin, 104(3), 348-362.

Brogden, W. J., Lipman, E. A., \& Culler, E. (1938). The role of incentive in conditioning and extinction. American Journal of Psychology, 51, 109-117.

Burch, M. R., \& Bailey, J. S. (1999). How dogs learn. New York: Howell Book House.

Campbell, P. E., Fixsen, D. L., \& Phillips, E. (1969). The reinstatement effect: Amount of noncontingent reward in the runway. Psychonomic Science, 14(5), 228-229.

Campbell, P. E., Phillips, E., Fixsen, D. L., \& Crumbaugh, C. (1968). Free operant response reinstatement during extinction and time-contingent (DRO) reward. Psychological Reports, 22, 563-569.

Catania, A. C. (1963). Concurrent performances: A baseline for the study of reinforcement magnitude. Journal of the Experimental Analysis of Behavior, 6(2), 299-300.

Crespi, L. P. (1942). Quantitative variation of incentive and performance in the white rat. The American Journal of Psychology, 55(4), 467-517.

Estes, W. K., \& Skinner, B. F. (1941). Some quantitative properties of anxiety. Journal of Experimental Psychology, 29(5), 390-400.

Flaherty, C. F. (1982). Incentive contrast: A review of behavioral changes following shifts in reward. Animal Learning \& Behavior, 10(4), 409-440.

Franks, G. J., \& Lattal, K. A. (1976). Antecedent reinforcement schedule training and operant response reinstatement in rats. Animal Learning \& Behavior, 4(4), 374-378.

Jenkins, H. M. (1965). Measurement of stimulus control during discriminative operant conditioning. Psychological Bulletin, 64, 365-376. 
Kamin, L. J. (1969). Predictability, surprise, attention, and conditioning. In B. A. Campbell \& R. M. Church (Eds.), Punishment and aversive behavior (pp. 279-296). New York: Appleton-Centry-Crofts.

Keesey, R. E., Kling, J. W. (1961). Amount of reinforcement and free-operant responding. Journal of the Experimental Analysis of Behavior, 4, 125-132.

Kello, J. E. (1972). The reinforcement-omission effect on fixed-interval schedules: Frustration or inhibition? Learning and Motivation, 3, 138-147.

Lattal, K. A. (1974). Combinations of response-reinforcer dependence and independence. Journal of the Experimental Analysis of Behavior, 22(2), 357-362.

Lattal, K. A., \& Abreu-Rodrigues, J. (1997). Response-independent events in the behavior stream. Journal of the Experimental Analysis of Behavior, 68(3), 375-398.

Lattal, K. A., \& Bryan, A. J. (1976). Effects of concurrent response-independent reinforcement on fixed-interval schedule performance. Journal of the Experimental Analysis of Behavior, 26(3), 495-504.

Lowe, C. F., Davey, G. C. L., \& Harzem, P. (1974). Effects of reinforcement magnitude on interval and ratio schedules. Journal of the Experimental Analysis of Behavior, 22(3), $553-560$.

Pryor, K. (1984). Don't shoot the dog! The new art of teaching and training. New York: Bantam Books.

Reid, R. L. (1958). The role of the reinforcer as a stimulus. British Journal of Psychology, 49, 202-209.

Rescorla, R. A., \& Wagner, A. R. (1972). A theory of Pavlovian conditioning: Variations in the effectiveness of reinforcement and nonreinforcement. In A. H. Black \& W. F. Prokosy 
(Eds.), Classical conditioning II: Current research and theory (pp. 64-99). New York: Appleton-Century-Crofts.

Schneider, B. A. (1969). A two-state analysis of fixed-interval responding in the pigeon. Journal of the Experimental Analysis of Behavior, 12(5), 677-687.

Schoenfeld, W. N. (1950). An experimental approach to anxiety, escape and avoidance behavior. In P.H. Hoch \& J. Zubin (Eds.), Anxiety (pp. 70-99). New York: Crune \& Stratton.

Shettleworth, S., \& Nevin, J. A. (1965). Relative rate of response and relative magnitude of reinforcement in multiple schedules. Journal of the Experimental Analysis of Behavior, 8(4), 199-202.

Staddon, J. E. R. (1970). Effect of reinforcement duration on fixed-interval responding. Journal of the Experimental Analysis of Behavior, 13(1), 9-11.

Staddon, J. E. R. (1972). Reinforcement omission on temporal go-no-go schedules. Journal of the Experimental Analysis of Behavior, 18(2), 223-229.

Staddon, J. E. R., \& Innis, N. K. (1969). Reinforcement omission on fixed-interval schedules. Journal of the Experimental Analysis of Behavior, 12(5), 689-700.

Tinklepaugh, O. L. (1928). An experimental study of representative factors in monkeys. Journal of Comparative Psychology, 8, 197-236.

Zeiler, M. D. (1968). Fixed and variable schedules of response-independent reinforcement. Journal of the Experimental Analysis of Behavior, 11(4), 405-414. 


\section{Footnote}

${ }^{1}$ In their original article, Lattal and Bryan (1976) used the term "concurrent." In the present paper, however, the term "concomitant" was used based on a suggestion made in the following article: Imam, A. A., \& Lattal, K. A. (1992). A suggestion for describing combination of response-dependent and response-independent events. The Behavior Analyst, 15(2), 179-192. 


\section{Med-PC Program}

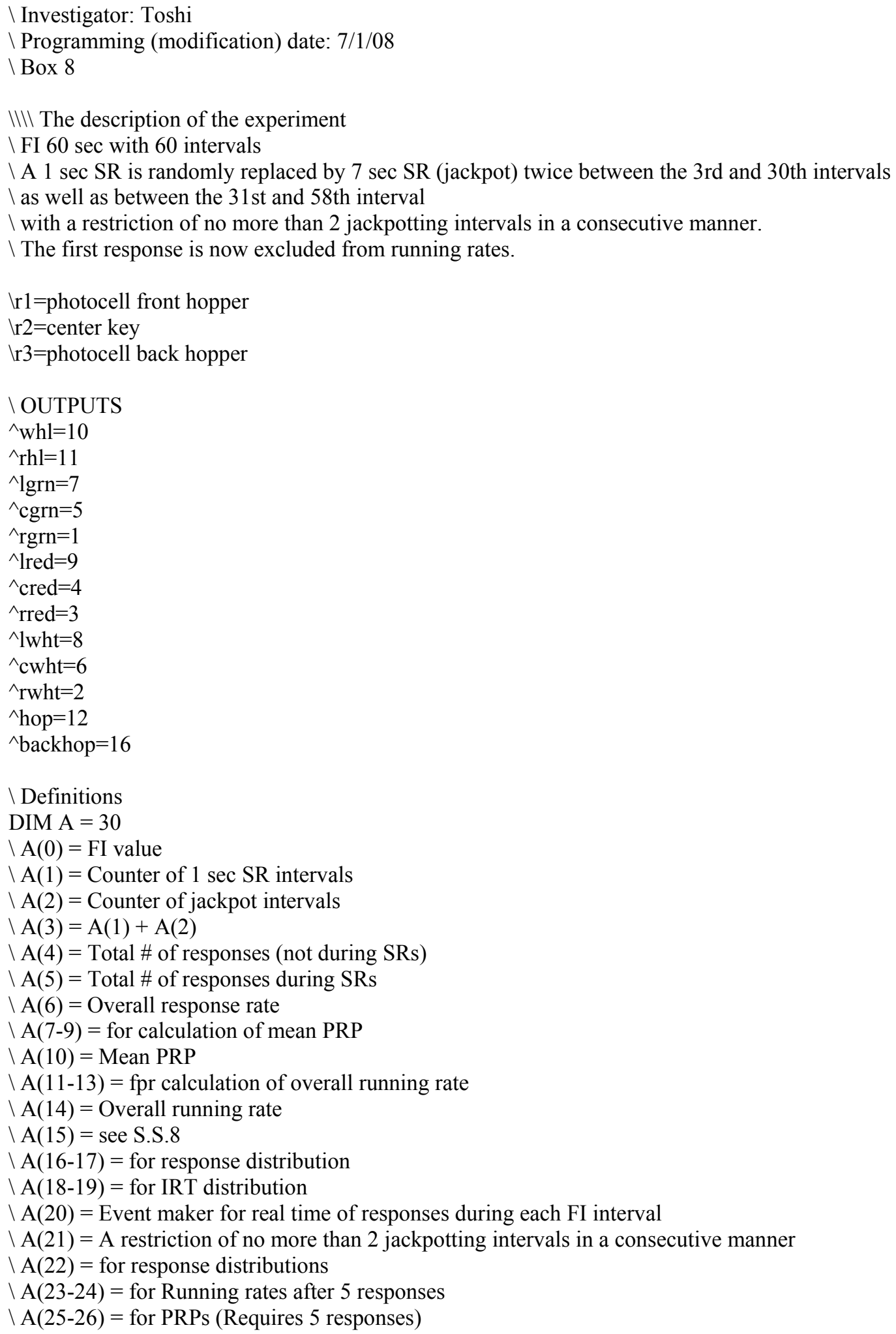


$\mathrm{DIM} \mathrm{B}=61 \backslash$ to record a sequence of FI intervals

$\backslash \mathrm{C}$ is index of $\mathrm{B}$

$\mathrm{DIM} \mathrm{D}=8000 \backslash$ Real time of responses during each FI interval

$\backslash \mathrm{E}$ is index of $\mathrm{D}$

DIM F $=6 \quad \backslash$ Flags

$\backslash \mathrm{F}(0)=$ for hopper $(0=$ off; $1=$ on $)$

$\backslash \mathrm{F}(1)=$ A restriction of no more than 2 jackpotting intervals in a consecutive manner $(0=\mathrm{OK} ; 1=$ restriction $)$

$\backslash \mathrm{F}(2)=$

$\backslash \mathrm{F}(3)=$

$\backslash \mathrm{F}(5)=$ for Running rates after 5 responses

DIM J $=61 \quad \backslash$ Local response rates

$\backslash \mathrm{K}$ is index of $\mathrm{J}$

DIM $\mathrm{M}=61 \quad \backslash$ PRPs

$\backslash \mathrm{N}$ is index of $\mathrm{M}$

$\mathrm{DIM} \mathrm{O}=61 \backslash$ Local running rates

$\backslash \mathrm{P}$ is index of $\mathrm{O}$

$\mathrm{DIM} Q=20000 \backslash$ Real time for every single event

$\backslash \mathrm{R}$ is index of $\mathrm{Q}$

$\backslash$ Response distribution for post-jackpot \& post-SR

$\wedge_{\text {start }}=0$

$\wedge$ end $=20$

DIM I $=20$

DIM U $=20$

$\backslash$ Response distributions

$\wedge$ startRD $=0$

$\wedge$ endRD $=722$

DIM H $=722$

$\backslash$ Response distributions (1 sec intervals)

$\wedge$ startRDprecise $=0$

$\wedge$ endRDprecise $=3602$

DIM S = 3602

$\backslash$ Cumulative recorder

$\mathrm{DIM} \mathrm{V}=8000 \backslash \mathrm{X}$ is index

$\backslash$ for Running rates and PRPs after 5 responses

DIM Z $=60$

DIM Y $=60$

$\backslash$ Alphabet leftover: W

DIM T $=15$

$\backslash \mathrm{T}(0)=$ Blackout timer

$\backslash \mathrm{T}(1)=$ Session timer

$\backslash \mathrm{T}(2)=$ see S.S.8

$\backslash \mathrm{T}(3)=$ see S.S.8 


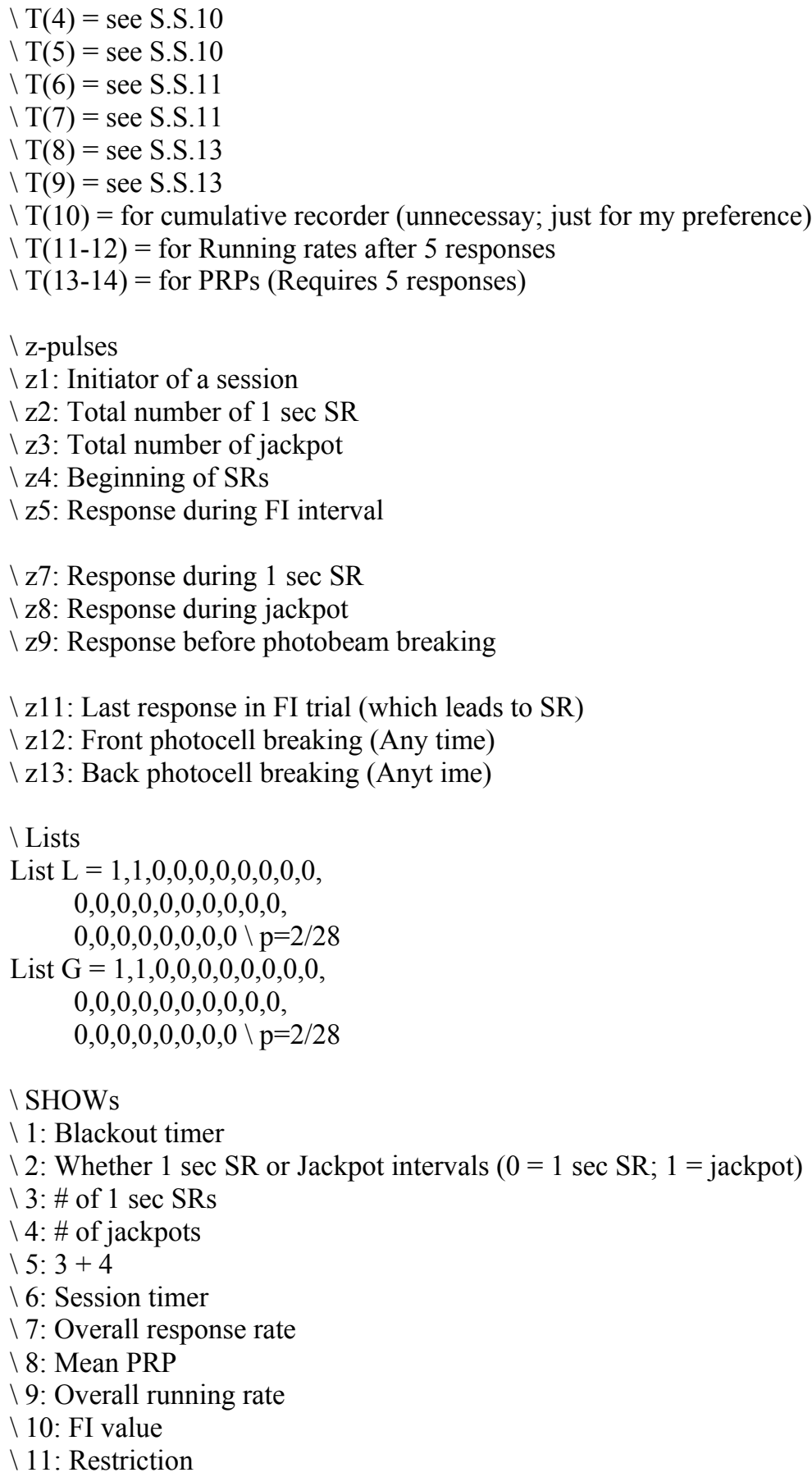

$\mid * * * * * * * * * * * * * * * * * * * * * * * * * * * * * * * * * * * * * * * * * * * * * * * * * * * * * * * * * * * * * * * * * * * * * * * * * * * * * * * * * * * * * * * * * * *$

S.S.1, $\backslash$ Box test

S1,

1": on ^cred ---> S2

S2,

3\#r2: off ${ }^{\wedge}$ cred; on ${ }^{\wedge}$ hop ---> S3

S3,

\#r1: ---> S4

S4, 


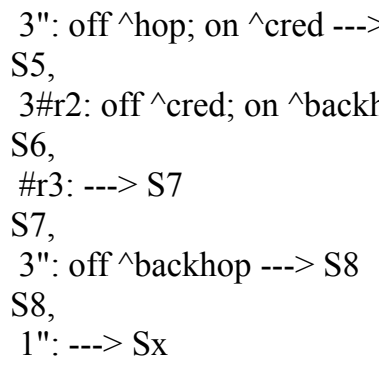

$\mid * * * * * * * * * * * * * * * * * * * * * * * * * * * * * * * * * * * * * * * * * * * * * * * * * * * * * * * * * * * * * * * * * * * * * * * * * * * * * * * * * * * * * * * * * *$ S.S.2, \Basic schedule: FI schedule

S1,

\#START: set $\mathrm{T}(0)=300, \mathrm{~F}(0)=0, \mathrm{C}=1$; show 1, Blackout, $\mathrm{T}(0)$---> S2

$\mathrm{S} 2$,

1": sub T(0); show 1, Blackout, T(0); if T(0)>0 [@true, @false]

@.true: ---> Sx

@false: on ${ }^{\wedge}$ cred; set $\mathrm{A}(0)=600, \mathrm{~B}(\mathrm{C})=0$; show 2, Jackpot, $\mathrm{B}(\mathrm{C})$; $\mathrm{z} 1$---> S3

S3,

0.1": sub A(0); show 10, FI, A(0); if A(0)<=0 [@true, @false]

$$
\text { @.true: ---> S4 }
$$

\#r2: z5 ---> Sx

@) false: ---> Sx

S4,

$\# \mathrm{r} 2: \mathrm{z} 11$; off $\wedge$ cred; if B(C)=0 [@normal, @jackpot]

(a) normal: on ^hop ---> S5

S5,

@ jackpot: on ${ }^{\wedge}$ backhop ---> S8

$.01 "$ ": set $\mathrm{F}(0)=1 ; \mathrm{z} 4$---> S6 $\backslash$ This is for not shooting $\mathrm{z} 4$ and $\mathrm{z} 5$ at the same time

S6,

\#r1:---> S7

$\#$ 2: z9 ---> Sx

$\mathrm{S} 7, \backslash$ if $\mathrm{F}(1)=0$, then it's OK. If $\mathrm{F}(1)=1$, then there is a rescriction

1": set $\mathrm{F}(0)=0, \mathrm{~A}(0)=600$; off ^hop; on ^cred; z2; add C;

if C >=3 [@more than 2, @1 or 2]

@ more than 2: if $\mathrm{C}>=31$ [@more than 30,@30 or less]

@more than 30: if C >=59 [@59 or 60,@58 or less]

@, 59 or 60 : set $\mathrm{B}(\mathrm{C})=0$; show 2, Jackpot, $\mathrm{B}(\mathrm{C})--->\mathrm{S} 3$

@ 58 or less: randd $\mathrm{B}(\mathrm{C})=\mathrm{G}$; show 2 , Jackpot, $\mathrm{B}(\mathrm{C})$---> S3

@ 30 or less: randd $\mathrm{B}(\mathrm{C})=\mathrm{L}$; show 2, Jackpot, $\mathrm{B}(\mathrm{C})$---> S3

\#r2: z7 ---> Sx

@ 1 or 2: set $\mathrm{B}(\mathrm{C})=0$; show 2, Jackpot, $\mathrm{B}(\mathrm{C})$---> S3

S8,

$.01 "$ : set $\mathrm{F}(0)=1 ; \mathrm{z} 4$---> S9 $\backslash$ This is for not shooting $\mathrm{z} 4$ and $\mathrm{z} 5$ at the same time

S9,

\#r3: ---> S10

$\#$ 2: $\mathrm{z} 9$---> Sx

S10,

7": set $\mathrm{F}(0)=0, \mathrm{~A}(0)=600$; off ${ }^{\wedge}$ backhop; on ${ }^{\wedge}$ cred; z3; add C;

if $\mathrm{F}(1)=0$ [@OK, @restriction]

@ OK: if $\mathrm{C}>=3$ [@more than 2, @1 or 2]

@more than 2: if C >=31 [@more than 30,@30 or less]

@ more than 30: if C >=59 [@59 or 60, @58 or less]

@ 59 or 60 : set $\mathrm{B}(\mathrm{C})=0$; show 2, Jackpot, $\mathrm{B}(\mathrm{C})$---> S3

(a) 58 or less: randd $\mathrm{B}(\mathrm{C})=\mathrm{G}$; show 2, Jackpot, $\mathrm{B}(\mathrm{C})$---> S3 
@ 30 or less: randd $\mathrm{B}(\mathrm{C})=\mathrm{L}$; show 2 , Jackpot, $\mathrm{B}(\mathrm{C})$---> S3

@1 or 2: set $\mathrm{B}(\mathrm{C})=0$; show 2, Jackpot, $\mathrm{B}(\mathrm{C})$--- $>\mathrm{S} 3$

@restriction: set $\mathrm{B}(\mathrm{C})=0$; show 2, Jackpot, $\mathrm{B}(\mathrm{C})$---> S3

\#r2: z8 ---> Sx

$\backslash * * * * * * * * * * * * * * * * * * * * * * * * * * * * * * * * * * * * * * * * * * * * * * * * * * * * * * * * * * * * * * * * * * * * * * * * * * * * * * * * * * * * * * * * * *$

S.S.3, \Counter of $1 \mathrm{sec}$ SR \& jackpot intervals

S1,

\#z1: set $\mathrm{A}(1)=0, \mathrm{~A}(2)=0$; show 3, 1-sSR, $\mathrm{A}(1)$; show 4, 7-sSR, A(2) ---> S2

S2,

\#z2: add A(1); show 3, 1-sSR, A(1) ---> Sx

\#z3: add A(2); show 4, 7-sSR, A(2) ---> Sx

\#z4: add A(3); show 5, TotalSR, A(3); if A(3)<60; [@true, @false]

@.true: ---> Sx

include the last 1-s SR

@ afalse: set $\mathrm{V}(\mathrm{X})=-987.987$; add $\mathrm{A}(1)$; show 3, 1-sSR, $\mathrm{A}(1)$---> S3 $\ \backslash$ This is to

S3,

.01": if $\mathrm{F}(0)=0$ [@off, @on]

(a) off: ---> STOPABORTFLUSH

@on: ---> Sx

$\backslash * * * * * * * * * * * * * * * * * * * * * * * * * * * * * * * * * * * * * * * * * * * * * * * * * * * * * * * * * * * * * * * * * * * * * * * * * * * * * * * * * * * * * * * * * *$

S.S.4, $\backslash$ Session Timer (Excludes SR time)

S1,

\#z1: set $\mathrm{T}(1)=0$; show 6 , SessionTimer, $\mathrm{T}(1)$---> S2

$\mathrm{S} 2$,

1": if $\mathrm{F}(0)=0$ [@off, @on]

@off: ADD T(1); show 6, SessionTimer, T(1) ---> Sx

@on: ---> Sx

$\mid * * * * * * * * * * * * * * * * * * * * * * * * * * * * * * * * * * * * * * * * * * * * * * * * * * * * * * * * * * * * * * * * * * * * * * * * * * * * * * * * * * * * * * * * * *$

S.S.5, \Overall Response rate

S1,

\#z1: set A(4) $=0$---> S2

$\mathrm{S} 2$,

\#z5 ! \#z11: ADD A(4); if T(1)>0[@true,@false]

@ true: set $\mathrm{A}(6)=(\mathrm{A}(4) / \mathrm{T}(1)) * 60$;

show 7, OverallRespRate, A(6) ---> Sx

@ false: ---> Sx

$\mid * * * * * * * * * * * * * * * * * * * * * * * * * * * * * * * * * * * * * * * * * * * * * * * * * * * * * * * * * * * * * * * * * * * * * * * * * * * * * * * * * * * * * * * * * *$

S.S.6, \Mean PRP ||$I \backslash \backslash$ Excludes the pause in the first FI trial

S1,

\#z1: $\operatorname{set} \mathrm{A}(7)=0, \mathrm{~A}(9)=1--->\mathrm{S} 2$

S2,

\#z2! \#z3:---- S3

$\mathrm{S} 3$,

$.01 ":$ add $\mathrm{A}(7) ;$ set $\mathrm{A}(8)=\mathrm{A}(7) / 100--->\mathrm{Sx}$

\#z5 ! \#z11: set A(10) = A(8)/A(9); show 8, MeanPRP, A(10); add A(9) ---> S2

$\mid * * * * * * * * * * * * * * * * * * * * * * * * * * * * * * * * * * * * * * * * * * * * * * * * * * * * * * * * * * * * * * * * * * * * * * * * * * * * * * * * * * * * * * * * * *$

S.S.7, \Overall Running rate

$\mathrm{S} 1$,

$\# \mathrm{Z} 1$ : set $\mathrm{A}(11)=0, \mathrm{~F}(3)=0$---> S2

$\mathrm{S} 2$, 


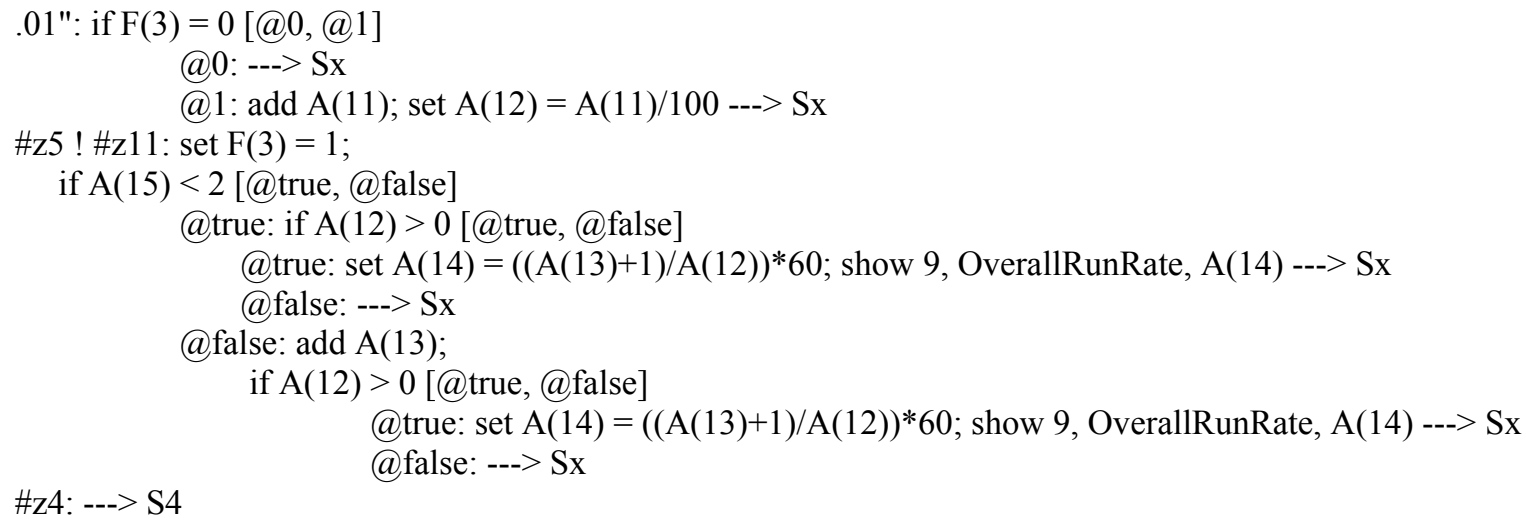

S4,

$\#$ z2 ! \#z3: set F(3) = 0 ---> S2

|********************************************************************************************** S.S.8, \Real time of responses during each FI interval $\backslash \backslash$ Actual data is (x 0.1); this is for event makers (effective from June 22 2008)

S1,

$\# \mathrm{z} 1:$ set $\mathrm{T}(2)=0, \mathrm{~A}(20)=1, \mathrm{~A}(15)=0--->\mathrm{S} 2$

$\mathrm{S} 2$,

\#z5 ! \#z11: add A(15); set $\mathrm{D}(\mathrm{E})=\mathrm{T}(3)+(\mathrm{A}(20) / 1000)$; add $\mathrm{E}$; set $\mathrm{D}(\mathrm{E})=-987.987--->\mathrm{Sx}$

.01 ": add $\mathrm{T}(2) ; \operatorname{set} \mathrm{T}(3)=\mathrm{T}(2) / 10--->\mathrm{Sx}$

\#z4: ---> S3

S3,

$\#$ z2 ! \#z3: set $\mathrm{T}(2)=0, \mathrm{~A}(15)=0 ;$ add $\mathrm{A}(20)--->\mathrm{S} 2$

$\mid * * * * * * * * * * * * * * * * * * * * * * * * * * * * * * * * * * * * * * * * * * * * * * * * * * * * * * * * * * * * * * * * * * * * * * * * * * * * * * * * * * * * * * * * * *$ S.S.9, \Local response rates

$\mathrm{S} 1$,

\#z1: set $\mathrm{K}=1$---> S2

$\mathrm{S} 2$,

\#z4: set $\mathrm{J}(\mathrm{K})=(\mathrm{A}(15) / \mathrm{T}(3)) * 60$; add $\mathrm{K}$---> S3

$\mathrm{S} 3$,

\#z2! \#z3:---> S2

$\backslash * * * * * * * * * * * * * * * * * * * * * * * * * * * * * * * * * * * * * * * * * * * * * * * * * * * * * * * * * * * * * * * * * * * * * * * * * * * * * * * * * * * * * * * * * *$

S.S.10, $\backslash$ PRPs for each FI interval

S1,

\#z1: set $\mathrm{T}(4)=0, \mathrm{~N}=1--->\mathrm{S} 2$

$\mathrm{S} 2$,

$.01 "$ ": add $\mathrm{T}(4) ; \operatorname{set} \mathrm{T}(5)=\mathrm{T}(4) / 100$---> Sx

$\# \mathrm{z} 5$ ! \#z11: set $\mathrm{M}(\mathrm{N})=\mathrm{T}(5) ; \operatorname{add} \mathrm{N} ; \operatorname{set} \mathrm{T}(4)=0$---> S3

S3,

\#z2! \#z3: ---> S2

$\mid * * * * * * * * * * * * * * * * * * * * * * * * * * * * * * * * * * * * * * * * * * * * * * * * * * * * * * * * * * * * * * * * * * * * * * * * * * * * * * * * * * * * * * * * * *$

S.S.11, $\backslash$ Local running rates [Excludes first response $=\mathrm{A}(15)-1$, from $06 / 08 / 08]$

S1,

\#z1: set $\mathrm{T}(6)=0, \mathrm{P}=1, \mathrm{~F}(2)=0$---> S2

S2,

\#z5 ! \#z11: set $\mathrm{F}(2)=1--->\mathrm{Sx}$

.01": if F(2)=0 [@0,@1] 


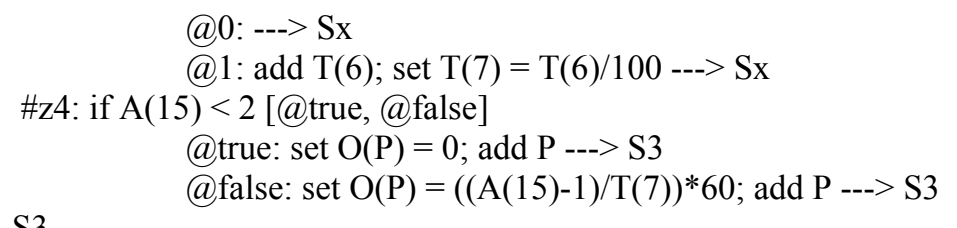

$\# \mathrm{z} 2$ ! \#z3: set $\mathrm{T}(6)=0, \mathrm{~F}(2)=0--->\mathrm{S} 2$

S.S.12, \Session Timer (includes SR time) \& Event makers

S1,

\#z1: set $\mathrm{T}(8)=0$---> S2

$\mathrm{S} 2$,

$.01 "$ ": add $\mathrm{T}(8) ; \operatorname{set} \mathrm{T}(9)=\mathrm{T}(8) / 100--->\mathrm{Sx}$

\#z5 ! \#z11: set $\mathrm{Q}(\mathrm{R})=\mathrm{T}(9)+.001$; add $\mathrm{R}$; set $\mathrm{Q}(\mathrm{R})=-987.987$---> Sx $\backslash \mathrm{z} 5$ : Response during FI interval

\#z4: set $\mathrm{Q}(\mathrm{R})=\mathrm{T}(9)+.002$; add $\mathrm{R}$; set $\mathrm{Q}(\mathrm{R})=-987.987$---> Sx $\backslash \mathrm{z} 4$ : Beginning of SRs

\#z9: set $\mathrm{Q}(\mathrm{R})=\mathrm{T}(9)+.003$; add $\mathrm{R}$; set $\mathrm{Q}(\mathrm{R})=-987.987$---> $\mathrm{Sx} \backslash \mathrm{z}$ : : Response before photobeam breaking

\#z12: set $Q(R)=T(9)+.004$; add $R ;$ set $Q(R)=-987.987$---> Sx $\backslash \mathrm{z} 12$ : Front Photobeam breaking (Any time)

\#z7: set $\mathrm{Q}(\mathrm{R})=\mathrm{T}(9)+.005$; add $\mathrm{R}$; set $\mathrm{Q}(\mathrm{R})=-987.987$---> Sx $\backslash \mathrm{z} 7$ : Response during $1 \mathrm{sec} \mathrm{SR}$

\#z2: set $\mathrm{Q}(\mathrm{R})=\mathrm{T}(9)+.006$; add $\mathrm{R} ;$ set $\mathrm{Q}(\mathrm{R})=-987.987$---> Sx $\backslash \mathrm{z} 2$ : End of $1 \mathrm{sec} \mathrm{SR}$

\#z8: set $\mathrm{Q}(\mathrm{R})=\mathrm{T}(9)+.007$; add $\mathrm{R}$; set $\mathrm{Q}(\mathrm{R})=-987.987$---> $\mathrm{Sx} \backslash \mathrm{z} 8$ : Response during jackpot

\#z3: set $\mathrm{Q}(\mathrm{R})=\mathrm{T}(9)+.008$; add $\mathrm{R}$; set $\mathrm{Q}(\mathrm{R})=-987.987$---> $\mathrm{Sx} \backslash \mathrm{z} 3$ : End of jackpot

\#z13: set $\mathrm{Q}(\mathrm{R})=\mathrm{T}(9)+.009$; add $\mathrm{R} ;$ set $\mathrm{Q}(\mathrm{R})=-987.987$---> $\mathrm{Sx} \backslash \mathrm{z} 13$ : Back Photobeam breaking (Any time)

$\mid * * * * * * * * * * * * * * * * * * * * * * * * * * * * * * * * * * * * * * * * * * * * * * * * * * * * * * * * * * * * * * * * * * * * * * * * * * * * * * * * * * * * * * * * * *$

S.S.13, $\backslash$ Response distributions in FI intervals for post-Jackpot \& post-SR

S1,

\#z1: ---> S2 \goes to FI interval with SR

S2,

\#z5 ! \#z11: bin U, A(17), 0.1, 5,^start, ^end ---> Sx

$.1 ":$ add $\mathrm{A}(17)--->\mathrm{Sx}$

\#z4: set A(17) $=0$---> S4

S3,

\#z5! \#z11: bin I, A(16), 0.1, 5,^start, ^end ---> Sx

$.1 ":$ add $\mathrm{A}(16)--->\mathrm{Sx}$

\#z4: set A(16) = 0 ---> S4

S4,

\#z2: ---> S2 $\backslash$ Post-SR

\#z3: ---> S3 \Post-jackpot

$\backslash * * * * * * * * * * * * * * * * * * * * * * * * * * * * * * * * * * * * * * * * * * * * * * * * * * * * * * * * * * * * * * * * * * * * * * * * * * * * * * * * * * * * * * * * * *$

S.S.15, $\backslash$ A restriction of no more than 2 jackpotting intervals in a consecutive manner;

$\backslash$ if $\mathrm{F}(1)=0$, then it's $\mathrm{OK}$. If $\mathrm{F}(1)=1$, then there is a rescriction

S1,

$\# \mathrm{z} 1$ : set $\mathrm{A}(21)=0, \mathrm{~F}(1)=0--->\mathrm{S} 2$

S2,

\#z3: add A(21); show 11, Restriction, A(21); if A(21)>=2 [@true, @false]

@ true: set $\mathrm{F}(1)=1$---> Sx

@false: --->Sx

$\# \mathrm{z} 2$ : set $\mathrm{A}(21)=0, \mathrm{~F}(1)=0$; show 11, Restriction, $\mathrm{A}(21)--->\mathrm{Sx}$ 
S.S.16, \Response distributions for each FI interval

S1,

\#z1: set $\mathrm{A}(22)=0$---> S2 $\backslash$ goes to FI interval with SR

S2,

\#z5: if $\mathrm{A}(22)<6000 * \mathrm{C}$ [@true, @false]

@ true: bin $\mathrm{H}, \mathrm{A}(22), 0.01,5, \wedge$ startRD, ^endRD ---> Sx

@false: ---> Sx

.01": if $\mathrm{A}(22)<6000^{*} \mathrm{C}$ [@true, @false]

@ true: add A(22) ---> Sx

@false: ---> Sx

$\mid * * * * * * * * * * * * * * * * * * * * * * * * * * * * * * * * * * * * * * * * * * * * * * * * * * * * * * * * * * * * * * * * * * * * * * * * * * * * * * * * * * * * * * * * * *$

S.S.17, $\backslash$ Response distributions for each FI interval (1 sec intervals)

S1,

\#z1: set $\mathrm{A}(22)=0--->\mathrm{S} 2 \backslash$ goes to FI interval with SR

S2,

\#z5: if A(22)<6000*C [@true, @false]

@ true: bin S, A(22), 0.01, 1, ^startRDprecise, ^endRDprecise ---> Sx

@false: ---> Sx

$\backslash * * * * * * * * * * * * * * * * * * * * * * * * * * * * * * * * * * * * * * * * * * * * * * * * * * * * * * * * * * * * * * * * * * * * * * * * * * * * * * * * * * * * * * * * * *$

S.S.18, $\backslash$ Cumulative Recorder

$\mathrm{S} 1$,

\#z1: set $\mathrm{T}(10)=0$---> S2

S2,

$\backslash$ Steps

$\# \mathrm{z} 5$ ! \#z11! \#z9 ! \#z7! \#z8: set $\mathrm{V}(\mathrm{X})=\mathrm{T}(10)+0.1$; add $\mathrm{X}$---> Sx $\backslash$ Response during FI trial

$\# z 9$ : set $\mathrm{V}(\mathrm{X})=\mathrm{T}(10)+0.1$; add $\mathrm{X}$; set $\mathrm{V}(\mathrm{X})=\mathrm{T}(10)+0.21$; add $\mathrm{X}--->\mathrm{Sx} \backslash$ Response during

reinforcement/jackpot

$\backslash$ Pips

\#z4: if $\mathrm{B}(\mathrm{C})=0[$ @normal, @jackpot $] \backslash$ Beginning of reinforcement/jackpotting

@ normal: set $\mathrm{V}(\mathrm{X})=\mathrm{T}(10)+0.2$; add $\mathrm{X}--->\mathrm{Sx}$

@jackpot: set $\mathrm{V}(\mathrm{X})=\mathrm{T}(10)+0.2 ;$ add $\mathrm{X}$; set $\mathrm{V}(\mathrm{X})=\mathrm{T}(10)+0.22$; add $\mathrm{X}$---> Sx

\#z12: set $\mathrm{V}(\mathrm{X})=\mathrm{T}(10)+0.23$; add $\mathrm{X}--->\mathrm{Sx} \backslash$ Photocell breaking (Front)

\#z13: set $\mathrm{V}(\mathrm{X})=\mathrm{T}(10)+0.26$; add $\mathrm{X}$---> Sx $\backslash$ Photocell breaking (Back)

$\backslash$ Reset pen

$\# \mathrm{z} 2$ ! \#z3: set $\mathrm{V}(\mathrm{X})=\mathrm{T}(10)+0.31$; add $\mathrm{X}--->\mathrm{Sx} \backslash$ End of reinforcement/jackpotting (Reset pen down to 0 )

$\backslash$ Timer

$.1 ":$ add $\mathrm{T}(10)--->\mathrm{Sx}$

S.S.19, \Local running rates (after 5 responses)

S1,

\#z1: set $\mathrm{T}(11)=0, \mathrm{~A}(23)=1, \mathrm{~F}(5)=0$---> S2

$\mathrm{S} 2$,

\#z5! \#z11: add A(24);

if $\mathrm{A}(24)>=5$ [@true, @ false]

@ true: set F(5)=1 ---> Sx

@false: ---> Sx

.01": if $\mathrm{F}(5)=0[@ 0, @ 1]$ 


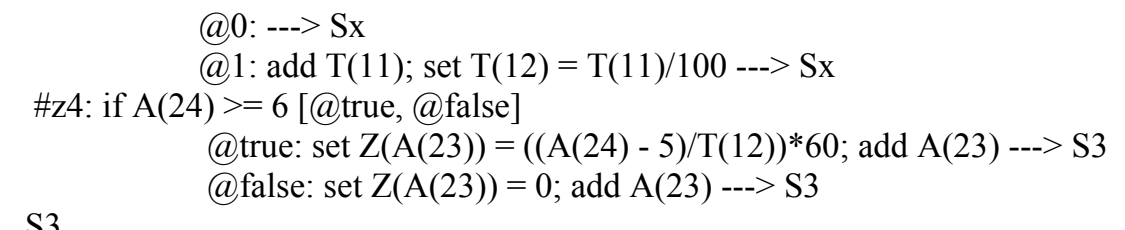

$\# \mathrm{z} 2$ ! \#z3: set $\mathrm{T}(11)=0, \mathrm{~A}(24)=0, \mathrm{~F}(5)=0--->\mathrm{S} 2$

$\mid * * * * * * * * * * * * * * * * * * * * * * * * * * * * * * * * * * * * * * * * * * * * * * * * * * * * * * * * * * * * * * * * * * * * * * * * * * * * * * * * * * * * * * * * * *$

S.S.20, \PRPs for each FI interval (Requires 5 responses)

$\mathrm{S} 1$,

\#z1: set $\mathrm{T}(13)=0, \mathrm{~A}(25)=1--->\mathrm{S} 2$

$\mathrm{S} 2$,

\#z5 ! \#z11: add A(26);

if $\mathrm{A}(26)=5$ [@true, @false]

@ true: set $\mathrm{Y}(\mathrm{A}(25))=\mathrm{T}(14)$; add $\mathrm{A}(25)$; set $\mathrm{T}(13)=0, \mathrm{~A}(26)=0$---> S3

@false: ---> Sx

$.01 ":$ add $\mathrm{T}(13)$; set $\mathrm{T}(14)=\mathrm{T}(13) / 100--->\mathrm{Sx}$

\#z4: if A(26)<5 [@true, @false]

@ true: set $\mathrm{Y}(\mathrm{A}(25))=0$; add $\mathrm{A}(25)$; set $\mathrm{T}(13)=0, \mathrm{~A}(26)=0$---> S3

@false: ---> S3

S3,

\#z2! \#z3:---- S2

S.S.21, $\backslash$ Just for sending z-pulse for front \& back photocell breaking during FI-interval

S1,

\#z1: ---> S2

S2,

\#r1: z12 ---> Sx Iphotocell front hopper

\#r3: z13 ---> Sx $\quad$ |photocell back hopper 